\title{
La teoría del azar, ¿nació por azar? ${ }^{1}$
}

\author{
ERnest Coumet
}

Uno de los más vivos debates metodológicos que recuerda la ciencia económica tuvo lugar en las páginas de Econometrica durante los años cincuenta, alrededor de un ensayo publicado por Daniel Bernoulli en $¡ 1738$ ! Apenas diez años antes, en 1943, John von Neumann recuperaba la solución que Bernoulli había dado a la paradoja de San Petersburgo, con una teoría axiomática de las funciones de utilidad elaborada, a instancias de Oskar Morgenstern, como complemento a su Theory of Games and Economic Behavior. Se trataba de dilucidar cuál debía ser el modelo matemático del comportamiento de un agente que decidía entre alternativas inciertas, y si tal modelo debía interpretarse descriptivamente o utilizarse de modo instrumental, normativo, etc; a ello contribuyeron, polémicamente, Maurice Allais, Milton Friedman, Leonard J. Savage, Paul Samuelson, John Milnor, y otros muchos sobresalientes economistas y matemáticos de la época.

En el curso de aquel debate algunas voces recordaron que el dilema no era nuevo: incierta era también la salvación para aquel jugador imaginado por Pas$\mathrm{cal}$, obligado a elegir entre los goces seculares que nos asegura la vida terrena, y la recompensa infinita, pero sólo probable, que la Iglesia promete a quien cumpla sus preceptos. La sugerencia de Georges-Théodule Guilbaud, introductor de la Teoría de juegos en Francia, a la vez que apasionado estudioso de su genealogía, no podía pasar desapercibida en un país de tan amplia y fecunda tradición como es el suyo, en lo que a la Historia y la Filosofía de las ciencias se refiere.

Así, conjugando el apunte de Guilbaud con una observación ocasional de Alexandre Koyré acerca de la apariencia jurfdica de la solución que Pascal

1 «La théorie du hasard, est-elle née par hasard?», Annales: Économies, Sociétés, Civilisations, 25 (1970), 574-598. 
diese al problema de los repartos (partis), Ernest Coumet ofrecía, veinte años después, su magistral análisis de la los orígenes jurídicos del concepto matemático de esperanza. Se trataba de interpretar en su contexto legal las dificultades que quisieron resolver matemáticamente la saga de los Fermat, Pascal, Huygens, etc. (como antes Galileo, Peverone, Cardano, etc.): cómo debía distribuirse lo apostado en un juego de azar que, por alguna razón, se interrumpía. Todo ello en un momento en que la ley era cosa de juristas que a menudo eran también teólogos, y la esperanza no era, desde luego, el momento de primer orden de una distribución de probabilidad.

La vía que abrió Coumet, con Guilbaud, Barbut, etc. desembocaría, diez años después, ya en los años ochenta, en los trabajos de M.Armatte, E.Brian, B.Bru, T.Martin, N.Meusnier y otros tantos autores de la Escuela parisina. Treinta años después de publicar su artículo, la Historia del cálculo de probabilidades es ya un disciplina consolidada, y el artículo de Coumet es ya uno de sus clásicos ${ }^{2}$, y como tal aun ofrece un buen número de interrogantes a todo aquel que se interese por los dilemas que plantea la investigación cuantitativa en las ciencias sociales ${ }^{3}$.

\author{
David Teira Serrano \\ Marta Garcia Alonso \\ UNED. Filosofía
}

«El origen del cálculo de probabilidades fue un problema relativo a los juegos de azar propuesto a un austero jansenista por un hombre de mundo» ${ }^{4}$. Este curioso aspecto del encuentro de Pascal y el caballero de Méré invita a la agudeza: no ha faltado quien lo celebrara como una afortunada casualidad. ¿No es maravilloso que un matemático de talento se encontrase allí en el momento justo para responder a las adivinanzas de un jugador, y aprovechase la ocasión ${ }^{5}$ para crear una nueva ciencia? Incluso Cournot, habitualmente

${ }^{2}$ En noviembre de 1999 el Centre Alexandre Koyré (EHESS) y el Centre International de Synthèse organizaron unas jornadas científicas en homenaje a Ernest Coumet, cuyas actas serán publicadas próximamente por la Revue de Synthèse.

${ }^{3}$ Para facilitar su lectura y estudio, incorporamos entre corchetes referencias bibliográficas actualizadas, traducciones de los pasajes citados en latín en el original, así como algunos otros simplemente aludidos en el texto. Agradecemos las orientaciones recibidas de los profesores $F$. Gómez Camacho, E. Lizcano, N. Meusnier, Q. Racionero, J.M. Rohrbasser, y J. Teira. Agradecemos también a Ernest Coumet su autorización para publicar esta traducción, que fue presentada originalmente en el Seminario de Estadística y Ciencias Sociales del Dpto.Sociología I (UNED).

4 S.-D.Poisson, Recherches sur la probabilité des jugements en matière criminelle et en matiere civile (París: Bachelier, 1837), p. 1.

5 «Los matemáticos de nuestra época han comenzado a interesarse por los azares con ocasión de los juegos. El caballero de Mére (...) dio lugar a ello al plantearse cuestiones sobre las partidas [los repartos] (...)" (Leibniz, Nouveaux Essais sur l'entendement humain, editado en 
tan sobrio, se permite un juego de palabras; pero acaso nos sorprenda aún más la observación que añade: aunque hizo falta esperar a Pascal para que se fundara la teoría matemática del azar, «este retraso es un puro efecto del azar, puesto que nada impedía que un griego de Cos o de Alejandría tuviese tanta afición a especular sobre las probabilidades como a la especulación sobre el cono» ${ }^{6}$. Aun cuando la invención del cálculo infinitesimal o de la mecánica racional sólo podía producirse «al cabo de un largo proceso de elaboración científica», el sutil espíritu de los griegos bien pudo haber resuelto todos los problemas que excitaron la curiosidad de Pascal y Fermat ${ }^{7}$.

$\mathrm{Y}$ a la inversa, se ha llegado a decir, recientemente, que fue necesario esperar a que llegase la moderna teoría de juegos para que el descubrimiento de Pascal manifestara su verdadera entidad. Una fecha señalada en la Historia de las ciencias humanas es la de la aparición del libro de von Neumann y Morgenstern Theory of Games and Economic Behavior ${ }^{8}$. Pese a las apariencias, no se trata de una teoría particular, ni de un instrumento matemático inédito que se ofrezca en exclusiva a los economistas. Junto a las teorías de la decisión estadística fundadas por Neyman y Wald, la teoría de juegos nos abre una vía para abordar de otro modo los problemas, es una nueva forma de pensar la organización racional de la acción humana. Desde hace algunos años, la mayor parte de los especialistas conviene en considerar bien la cibernética, bien la investigación operativa, como ciencia de la dirección de la acción.

No se trata solamente de ofrecer un recetario, sino de construir modelos generales que describan adecuadamente el comportamiento humano (que es siempre, en uno u otro grado, un proceso de decisión y elección), y puedan, por tanto, servir de base para tomar decisiones en situaciones complejas. Pues bien, en el momento mismo en que G.-Th.Guilbaud difundía en Francia las nuevas posibilidades que la teoría de la decisión abría a las ciencias sociales, recordaba también su dimensión secular: este punto de vista revolucionario era ya el de Pascal ${ }^{9}$. Una misma inspiración habría guiado también a Jacques Bernoulli, Buffon, Condorcet y muchos otros probabilistas que vieron en el cálculo de la probabilidad el instrumento por excelencia de la razón aplicada a los «asuntos de la vida civil»: debía ayudar a los hombres a mejorar su elección

Euvres philosophiques de Leibniz, ed.Janet [París: Librairie philosophique de Ladrange, 1866] vol.1, p.496)). [Edición española de Javier Echeverría: Nuevos ensayos sobre el entendimiento humano, Libro IV, capítulo XVI, \& 10 (Madrid: Alianza, 1992), pp. 561-562].

6 A.A.Cournot, Matérialisme, vitalisme, rationalisme. Études sur l'emploi des données de la science en philosophie (París: Hachette, 1875), p.315. [Hay una edición reciente a cargo de Claire Salomon-Bayet, París: J.Vrin, 1987].

7 A.A.Cournot, Considérat ions sur la marche des idées et des événements dans les temps modernes (París: Boivin \& Cie., 1934), vol.I, pp.234-235. [Hay una edición más reciente a cargo de A.Robinet en A.A.Cournot, Ouvres Completes, vol.IV (París: J.Vrin, 1973)].

8 [Princeton: Princeton University Press, '1944].

9 En dos artículos fundamentales: «Les problèmes de partage. Matériaux pour une enquête sur les algèbres et les arithmétiques de la répartition», Economie appliquée, V.1 (1952), 93137; «Les théories de l'intérêt général et le problème logique de l'agrégation», Economie appliquée , V.4 (1952), 501-584. [Ambos fueron reeditados en G.Th.Guilbaud, Eléments de la théorie mathématique des jeux (Paris: Dunod, 1968)]. 
allí donde la intervención del azar les confundiese. Lo que sumió en el olvido esta corriente de pensamiento fue la apropiación en exclusiva de este cálculo por parte de la física en el siglo XIX, de modo que quienes lo empleaban en sociología o en economía política, lo hacían en calidad de físicos. Si la teoría de la decisión y las disciplinas que inspira quieren entroncar con sus verdaderos orígenes, deben empezar rindiendo homenaje a su auténtico fundador: Pascal ${ }^{10}$. El problema de los repartos (problème des partis) dice G.-Th.Guilbaud, es un problema de decisión: si las reglas del juego contemplasen todos los posibles resultados, sabríamos repartir lo apostado al términar la partida; pero si la interrumpimos antes, ¿cómo repartirlo? Es preciso resolver un caso imprevisto, tomar una decisión. Para ello, es necesario saber medir las probabilidades, pero este conocimiento no es sino un medio al servicio de la ciencia que Bernoulli denominó Estocástica. Para sus fundadores, el cálculo de probabilidades estaba, como vemos, muy próximo en espíritu a la praxeología contemporánea ${ }^{11}$.

Pero ¿qué dirá de todo ello el historiador, que sabe bien a qué errores nos puede abocar nuestra propensión a proyectar sobre el pasado nuestras actuales preocupaciones? ¿Está bien atestiguada la genealogía que se atribuyen estos recién llegados? Y especialmente, ¿se podrían decir, en justicia, pascalianos, si éste hubiese encontrado casualmente el problema de los repartos, si sólo concerniese a éste, en particular, la cuestión «de decidir», tal como nosotros la interpretamos, y se debiera, por decirlo con Cournot, a un simple «azar histórico»? Sería muy distinto si se tratase, por el contrario, de uno de los signos más evidentes de un vasto movimiento intelectual, el reflejo de un momento histórico, en suma. Por nuestra parte, intentaremos establecer si esto que en apariencia no es más que un pequeño «problema», en el sentido que le dan los matemáticos, se inscribe en una temática mucho más amplia.

\section{EQUIDAD Y SUERTES DIVISORIAS}

$\mathrm{El}$ «Usage du triangle arithmétique pour déterminer les partys qu'on doit faire entre deux joüeurs qui joüent en plusieurs parties» 12 es un sorprenden-

${ }^{10}$ Así lo hicieron, tras la aparición de los artículos de G.-Th.Guilbaud, todos los autores que al hablar de investigación operativa, de cibernética, de teoría de juegos, etc., echaban una ojeada al pasado. Cf., por ejemplo: A. Kaufmann, R. Fauré y A. Le Garff, Les jeux d'entreprise (París: PUF, 1960), p.22; R. Faure, J.P. Boss y A. Le Garf, La recherche operationelle (París: PUF, 1961), p. 6; P. Rosenstiehl y J. Mothes, Mathématiques de l'action (París: Dunod, 1965), pp. 275-ss, inician la exposición de «la esperanza matemática de un azar numérico» con un análisis de la "regla de los repartos» de Pascal.

11 G.Th.Guilbaud, op.cit.

12 Citamos por la edición de las Euvres de Blaise Pascal, en 14 volúmenes editada por L. Brunschvicg, P. Boutroux y F. Gazier (París, 1908-1914), a la que nos referiremos con las siglas G.E. Así para el Usage..., G.E., vol. III, pp. 478-503 [La versión española que seguiremos es la de Carlos R.de Dampierre: Blaise Pascal, Obras (Madrid: Alfaguara, 1981), que citaremos como Obras. Así, el «Uso del triángulo aritmético para determinar los repartos que se deben hacer entre dos jugadores que juegan varias partidas» se encuentra en Obras, pp. 692-705]. 
te escrito de juventud. Ninguna consideración extemporánea enturbia el rigor de la demostración, ni tan siquiera la sobriedad del enunciado: ninguna observación sobre el alcance del descubrimiento que allí se expone, calificado por el mismo Pascal como «pasmoso» (stupendum) en su Adresse à l'Académie Parisienne; menos aún digresiones sobre la fortuna, como las de Cardano, uno de los predecesores de Pascal. Todo es necesario en la exposición, y no se omite nada imprescindible para obtener la solución: lejos de disimular su método, Pascal lo ha reducido a sus «principios». Al comienzo de su demostración, formula incluso el caso «trivial», pues considera que es preciso «empezar por el principio» ${ }^{13}$ : se podría asociar su proceder con el de nuestros modernos bourbakistas. $Y$ un soberano «al infinito» ${ }^{14}$ acaba de convencernos de que, en el fondo, poco importa si es cuestión de repartos y jugadores: este Usage ilustra, entre otras aplicaciones, la potencia de esa maravillosa máquina de pensar que es el Triángulo Aritmético.

Por tanto, no nos sorprenderá la forma en que tradicionalmente se ha presentado el origen del cálculo de probabilidades. Puesto que se trataba de un problema bien definido se buscaron algunos precursores, y se encontraron: habían fracasado. En cambio, Pascal y Fermat hicieron lo que se puede esperar de los genios: hallaron la solución. Lo hicieron tan bien que incluso ocultaron su problema a la curiosidad de los historiadores. Éstos no han sabido atribuirle otra función que la de haber servido de ejercicio o de pretexto.

Reducido de ese modo a su significado más elemental, casi parece surgir de la nada. «Azar histórico», dice Cournot. No hará falta preguntarse si es preciso añadir al acervo de la sutileza griega un descubrimiento que bien «habría podido realizar». Nada más difícil de refutar, por lo demás, que este tipo de ucronias. Sin embargo, se admitirá con mayores reservas que los problemas geométricos sean considerados de igual dificultad que aquellos otros en los que interviene el azar, si bien la dificultad no es en ambos casos de la misma naturaleza. Fue necesaria una profunda modificación de la Lógica aristotélica para que se desarrollase el anális combinatorio ${ }^{15}$, pero no menos profunda fue la mutación mental (mutation mental) sin la que no hubiese surgido la posibilidad de matematizar los juegos de azar. No son necesarios estudios etnograficos muy eruditos para imaginar los obstáculos con los que podía haber topado esta matematización. Las palabras oportunidad (chance), suerte (sort), azar (hasard)... tienen, aún en nuestros días, una resonancia peculiar que hace innecesario insistir en este aspecto. Pero es menos conocido que la naturaleza de los juegos de azar planteó un problema muy preciso a la teología cristiana. Era por todos admitido que las Sagradas Escrituras estaban atestadas de casos en

${ }^{13}$ G.E., III, p.482 [Obras, p.695].

${ }^{14}$ G.E., III, p.485 [Obras, p.697].

15 «El cálculo combinatorio es importante para la ciencia matemática del siglo XVII: exige la legitimación de un cálculo de relaciones como cálculo de objetos, y supone, por tanto, un triunfo sobre la lógica antigua que no aceptaba más que sujetos y predicados» (Joachim-Otto Fleckenstein, «Petrus Ramus et l'Humanisme balois», en VV.AA., La science au seizieme siècle. [Colloque de Royaumont, juillet 1957] [París: Hermann, 1960], p. 120). 
los que Dios había manifestado su voluntad por mediación de la suerte. Era, pues, posible y legítimo recurrir a esta vía para consultarle: la única dificultad era definir los casos en que era lícito. Así, Santo Tomás distingue entre suertes consultivas, suertes adivinatorias y suertes divisorias (sortes divisoria). Estas últimas eran aquellas a las que uno recurre para decidir a quién debe ser devuelta una cosa, o lo que se le debe atribuir como propio (posesiones, honores o dignidades). En caso de necesidad, está permitido implorar, con la debida reverencia, el juicio de Dios por la vía de la suerte. Si tales condiciones no son respetadas, estamos ante un pecado grave, pues se trata entonces de una manera de tentar a Dios. En virtud de esta prohibición, los juegos de azar se condenarán vehementemente, según una doctrina que aún tendrá seguidores en el siglo XVIII: son perniciosos por naturaleza pues «profanan la Suerte».

Para poder especular matemáticamente sobre los juegos de azar era necesario que abandonasen antes el ámbito de lo sagrado por el círculo de los asuntos puramente humanos. No por ello dejaron de padecer otro género de condena que nos interesa directamente, en la medida en que Pascal habla de los juegos en términos de convenciones. Los juegos de azar, dirán numerosos teólogos y juristas, son convenciones ilícitas, pues en el juego el dinero ganado lo es sin ninguna causa legítima, es un beneficio condenable por las mismas razones que la usura:

De tal manera que cualquiera que toma y retiene dinero de otro por haberlo ganado en el juego, lo retiene sin ninguna causa legítima, y lo tiene, por tanto, con mala conciencia y, a decir verdad, es un simple ladrón ${ }^{16}$.

¿Me diréis: «lo hemos convenido así»? Eso valdrá para mostrar que el ganador no engaña a los demás, pero de ello no se sigue que la convención y el juego sean razonables: pues la ganancia, que debe ser el premio de la industria, se convierte en premio de la suerte, que no merece ningún premio, puesto que no depende en modo alguno de nosotros ${ }^{17}$.

Los casuistas sostendrán lo contrario. Hablar del juego, se hiciera como se hiciese, era una cuestión muy controvertida. En la siguiente admonición que le dirigió a Pascal el abate Villars, la acusación es más pérfida de lo que parece, pues, en realidad, es muy precisa:

He oído decir, en efecto, que usted es un gran enemigo del casuismo laxista: cómo es entonces que usted no sólo no condena el juego, sino que

16 «Tellement que quiconque prent \& retient l'argent d'un autre pour l'avoir gagné au jeu, le retient sans aucune cause légitime, \& partant l'a en mauvaise conscience \& a vrayment dire en est un pur larron (...)» (Lambert Daneau, Brieve remostrance sur les jeux de sort ou de hazard, et principalement de dés et de cartes... [S.1.: Impr. de P.Prunier, 1591], pp. 9-10).

17 «Nous avons ainsi convenu, me direz vous? Cela est bon pour monstrer que celuy qui gaigne ne fait pas tort aux autres mais il ne s'ensuit pas que la convention ne soit déraisonnable, \& le jeu aussi: car le gain qui doit estre le prix de l'industrie est rendu le prix du sort, qui ne mérite nul prix puis qu'il ne depend nullement de nous» (San Francisco de Sales, Introduction d la vie devote, III parte, cap. 32 («Des jeux deffendus») [París: M.Henault, 1628], pp. 443-444). [Hay versión castellana: Introducción a la vida devota (Madrid: BAC, 1991)]. 
quiere incluso hacer depender la Religión y la Divinidad del juego de cara $\mathrm{y}_{\mathrm{cruz}}{ }^{18}$.

No hace falta que nos preocupemos aquí por el aspecto moral del problema, mas ¿no podría decirse que la «ley voluntaria» de la que habla Pascal está bastante próxima conceptualmente a las convenciones que, según los casuistas, conciernen al Derecho Natural?

Contemplando a vista de pájaro una evolución tan enredada, puede decirse que la licitud de los juegos de azar se estableció gracias a una doble operación: por una parte, las suertes divisorias se disociarán completamente de los otros tipos de suerte, perdiendo todo rasgo sobrenatural; por otra, se intentará ligar exclusivamente a ellas los juegos de azar.

Santo Tomás ya había considerado, ocasionalmente, el caso en que, al emplear suertes divisorias, no esperamos el resultado de Dios, sino simplemente del azar. El Aquinate no lo condena, pero la sospecha que levanta, al decir que tal vez no haya en ello otro mal que «lo que quizá tenga de frivolidad» ${ }^{19}$, hará que rigurosos moralistas extraigan de aquí argumentos contra los juegos de azar hasta el siglo XVIII. Y a la inversa, los casuistas sacarán el mayor partido a la posibilidad que Santo Tomás había dejado entrever: dejarlo a la suerte es, a menudo, el modo más natural de proceder en un reparto. Enumerarán los casos en los que efectivamente se acostumbra a proceder de este modo, tanto en la vida cotidiana como en las instituciones políticas. Irán aun más lejos, destacando el carácter imparcial de las decisiones así obtenidas: al usar bien las suertes divisorias, se pone en práctica una virtud moral. Les sirve de garantía un texto de San Agustín, que Santo Tomás había citado para legitimar los casos en los que está permitido implorar a Dios, aunque lo interpretarán de muy distinto modo ${ }^{20}$, reteniendo la idea de que, en ciertas ocasiones, al recurrir a la suerte ejercemos la virtud de la justicia. Se trata de

18 «Mais j'avois ouï dire que vous estiez si grand ennemi des Casuistes relâchez: $d$ 'oú vient que non seulement vous ne condamnez pas le jeu, mais que vous voulez faire dépendre la Religion \& la Divinité du jeu de croix et de pile» (Abate Villars, De la Délicatesse (París: Claude Barbin, 1671), p.352) [Véase D.Descotes, La Première critique des «Pensées*: texte et commentaire du cinquième dialogue du traité «De la Délicatesse» de l'abbé de Villars (1671) (París: Éditions du CNRS, 1980)].

19 Afirmaba Santo Tomás, después de haber descartado la influencia de los astros, que el resultado de la suerte no puede esperarse sino del azar o de una influencia espiritual que dirija su curso: «Et si quidem ex fortuna, quod locum habere potest solum in divisoria sorte, non videtur habere nisi forte vitium vanitatis: sicut si aliqui non valentes aliquid concorditer dividire, velint sortibus ad divisionem uti, quasi fortuna exponentes qui quam partem accipiat» (Somme Théologique, traducción francesa de I.Mennessier (París, Tournai, Roma: Desclée \& Cie., 1953), pp. 238-239) . [ «Si se atribuye tal resultado al azar, y esto puede ocurrir únicamente en la suerte divisoria, no parece que haya en esta práctica nada de mal, a no ser por lo que tal vez tenga de frivolidad. Tal es el caso de los que, no pudiendo ponerse de acuerdo en el reparto de una cosa, prefieren echarlo a suertes, dejando en manos del azar cuál es la parte que ha de recibir cada uno» (traducción de M.Morán Flecha, tomada de la edición en 5 volúmenes dirigida por los Regentes de Estudios de las Provincias Dominicanas de España: Suma de Teologia, II-II, q.95, a.8 [Madrid: BAC, 1994-1997], vol. IV, p. 146.)]

${ }^{20}$ Ibid., p. 242 [loc.cit.]. 
un pasaje del De Doctrina christiana: debemos ciertamente -dice San Agustín- igual amor a todos los hombres, pero nos es imposible hacer el bien a todos; por tanto, hemos de cuidarnos sobre todo de las personas a las que estemos más estrechamente unidos, según las circunstancias de tiempo o lugar, «como si lo eligiese la suerte»:

Vamos a suponer que te sobra una cosa, que debes dar a quien la necesita, y que es tal que no puede darse a dos. Si acuden a ti dos pobres, de los cuales ninguno tiene motivos de preferencia sobre el otro ni por razón de su indigencia ni por algún vínculo especial que lo relacione contigo, nada mejor puedes hacer en este caso que elegir por medio de la suerte (nihil justius faceres quam tu sorte legeres) a quién ha de darse lo que a los dos no se puede ${ }^{21}$.

Indudablemente, tal procedimiento sólo es justo si se dan unas condiciones bien determinadas: así, no se podrá elegir al azar más que entre personas cuyo merito se reconozca igual de antemano. Se produce así un importante cambio en favor de las suertes divisorias: no sólo se considerarán «suertes naturales» (sorts naturels), según la expresión que utilizará mucho después La Placette, sino que fundamentarán convenciones justas (conventions équitables).

De este mismo cambio se beneficiarán los juegos de azar, al clasificarse bajo la rúbrica de las suertes divisorias. Esta nueva clasificación no se redujo a un simple cambio de etiqueta: presupone nada menos que una nueva concepción del contrato y de la propiedad. Debía admitirse que estaba permitido, según el derecho natural, exponer un bien al azar; que la transferencia de propiedad causada únicamente por acontecer un suceso fortuito tenía un fundamento jurídico sólido. Los casuistas van a justificar ambas tesis desplazando el problema hacia el carácter equitativo de las convenciones características de los juegos. Desde un punto de vista moral, está establecido que una de las características esenciales que debe cumplir un juego, cualquiera que sea, es que los jugadores estén en «igualdad de condiciones». La justicia nos impone esta igualdad. Ahora bien, a ojos de quienes creen que el fundamento de un contrato reside en la voluntad de los contratantes, esta restricción puede servir de base a una justificación. Desde el punto de vista del derecho natural, no hay razón para oponerse a una convención justa en la que se equilibren riesgos y ventajas.

Primun ex forma non vitiatur jure naturæ: nam praeterquam quod posset uterque ludentium gratis donare, illa non est simplex donatio, sed quaedam pactio: Do tu Des, nempe meam pecuniam periculo expono, ut tu vicissim exponas tuam. Et tanti aestimatur periculum unius, quanti alterius ${ }^{22}$.

21 De Doctrina christiana, libro II, capítulo 28, $§ 29$ (Euvres de saint Augustin, 11, $1^{\text {er }}$ série, Opuscules 11 Texto de la edición benedictina, traducción francesa y notas del canónigo G. Cambès y el abate Farges [París: Desclée de Brouwer, 1949], pp. 215-216) [Recogemos la traducción de M. Morán (cf. supra nota 16). Hay una edición bilingùe, agotada, a cargo de $B$. Martín, O.S.A., en Obras de San Agustín, vol. XV (Madrid: BAC, 1957)].

22 Domingo de Soto, De Iustitia et lure Libri decem (Lyon: Haeredes J. Junctae, 1559), p. 230. Para Molina, que retomará este tema, en los juegos de azar intervienen no una, sino dos 
Este texto -después tendremos ocasión de ver cómo sigue- nos parece tan notable por su fecha (1559) como por la claridad con que expone una tesis que servirá de base a los casuistas y será integrada en el Derecho civil: los juegos de azar constituyen una especie de lo que más tarde se llamarán contratos aleatorios. Éstos se asientan en convenciones voluntarias, según las cuales la posesión del bien depende del resultado incierto de la fortuna, y para ser legítimas deben verificar ciertos criterios de equidad.

Pero como es una ley voluntaria pueden romperla de común acuerdo (...)

El dinero que los jugadores han puesto en el juego ya no les pertenece (...) ${ }^{23}$.

Por oscuras que resulten las observaciones que venimos haciendo, ¿no encuentran un eco muy particular en estas frases de Pascal? Indudablemente, Pascal no se planteaba el problema de la licitud de los juegos de azar: éste quedaba en suspenso, puesto que para él, un matemático, la actividad del juego aparecía como un objeto de reflexión, algo dado sobre lo cual no tenía que emitir juicio de valor alguno. No obstante, la neutralidad científica encuentra aquí otros límites: tal actividad no puede reducirse de golpe a términos matemáticos. Así, para formular su problema Pascal emplea las mismas expresiones, utiliza las mismas nociones que habían sido ya explotadas, algunas incluso creadas, por quienes habían intentado probar que los juegos de azar eran convenciones que debían regirse por la justicia. Se intuye ya cómo podría desarrollarse la observación que hacía Alexandre Koyré en el Congreso de Royaumont (1954): «En el problema de los repartos aparece la cuestion del derecho del jugador sobre lo apostado. Fermat era un jurista y Pascal vivía rodeado de juristas, y creo que esto les hizo más sensibles a este aspecto de un problema en el que Galileo no vio más que una simple cuestión de combinatoria» ${ }^{24}$. Entiéndase: no se trata de interpretar brutalmente en términos de influencia la relación que acabamos de establecer entre el lenguaje

virtudes morales: la justicia y la eutrapelia (De Iustitia et Iure [Maguncia, 1614], vol. 2, 1163D) [Edición facsimilar de la edición latina de 1556 y versión castellana en 5 volúmenes a cargo de Venancio Carro, O.P. (introducciones) y Marcelino González, O.P. (traducción): De la justicia y del derecho (Madrid: Instituto de Estudios Políticos, 1968). El texto citado se halla en la página 314, vol. II: «En cuanto a lo primero, por su forma no es inválido según el derecho natural; puesto que, además de que los dos jugadores pueden hacer donación gratuitamente de sus bienes, con todo aquí no hay sino cierto contrato: Do ut des. Es decir: yo expongo mi dinero, para que tú, a la vez, expongas el tuyo. Y tan grande es el peligro del dinero de uno como el del otro». Del De Iustitia et Iure de Luis de Molina existen diferentes ediciones parciales en castellano, aunque ninguna recoge los pasajes citados por Coumet.].

${ }_{23}$ [Obras, p. 692. El pasaje completo dice «Para comprender la regla de los repartos, la primera cosa que hay que considerar es que el dinero que los jugadores han puesto en juego ya no les pertenece, porque han renunciado a su propiedad; pero han recibido en revancha el derecho a esperar (droit d'attendre) lo que el azar les puede dar, de acuerdo con las condiciones que han convenido antes. Pero como es una ley voluntaria, pueden romperla de común acuerdo; y así, en cualquier fase que se encuentre el juego, pueden salirse de él; y, al revés de lo que han hecho al entrar, renunciar a la esperanza del azar (attente du hasard), y entrar cada cual en la propiedad de algo."]

${ }^{24}$ En el curso de la discusión que siguió a su conferencia «Pascal savant» (en VV.AA., Blaise Pascal, L'homme et l'auvre [Cahiers de Royaumont, Philosophie n. ${ }^{\circ}$ 1] [París: Minuit, 1956], p. 291). 
de ciertos juristas (la palabra asustará menos y será, por lo demás, más ajustada que casuistas) y el de Pascal. Podemos afirmar, en todo caso, que los conceptos en que se subsumen los juegos de azar son idénticos por ambas partes. Más aún: los moralistas que intentaban determinar las condiciones que debe cumplir un juego para que sea justo, se sitúan más allá del antagonismo y la codicia de los jugadores; el matemático que quiere calcular la «distribución justa» no hace sino retomar, con mayor rigor, la misma actitud: él es el árbitro.

\section{EL DERECHO Y LOS ACONTECIMIENTOS CASUALES}

Una vez examinado el aspecto contractual, concentrémonos ahora en el segundo elemento de las suertes divisorias y los juegos de azar: la «fortuna» (fortune). Lo que la fortuna decide no resulta de alguna voluntad particular de Dios, y no tiene nada en común con la diosa fortuna que tantos adoradores tuvo, en sus distintas formas, durante el Renacimiento. No distingue individuos esencialmente más «felices» que otros. Si las convenciones que basamos en sus resultados son justas, se debe su indiferencia. Se caracteriza por su incertidumbre ${ }^{25}$. Por tanto, en nada difiere de lo que los lógicos denominan precisamente «fortuna»: los acontecimientos que se producen en el transcurso de un juego de azar no son naturalmente distintos de lo que, en general, denominamos «acontecimientos contingentes». Esta relación nos parece tanto más interesante cuanto que, en los autores de los que nos ocupamos, se establece sin referencia a reflexión alguna sobre la naturaleza de los instrumentos aleatorios ${ }^{26}$ : en ambos dominios el hombre debe acomodarse a un mismo tipo de incertidumbre. Por tanto, para que los juegos de azar queden exonerados de las acusaciones formuladas contra ellos, bastará considerar aquellos casos en que interviene la fortuna sin que, no obstante, estén por ello condenados. Puesto que los doctores convienen en considerar lícitos los contratos de seguros, ¡habrán de ser consecuentes! ${ }^{27}$. Un signo plenamente material nos enseña

${ }^{25}$ He aquí la continuación del texto de Soto antes citado: «Neque vero condemnanda est: quia res ancipiti fortunæ committitur, hoc est eventui, cujus causa nescitur nisi a Deo: hoc enim modo nihil absurdi sonat inter Chritianos fortunæ nomen» (loc.cit.) [ «Y tampoco ha de condenarse que el asunto se encomiende a una suerte dudosa, es decir, a un suceso cuya causa solo conoce Dios; porque de este modo la palabra suerte no significa nada absurdo entre los cristianos» (loc.cit)] En su Adresse à l'Académie Parissiene, Pascal emplea la misma expresión anceps fortunae, y escribe después: «Ambiguae enim sortis eventus fortuitæ contingentia potius quam naturali necessitati merito tribuuntur» (G.E., III, p. 307). [El Discurso a la Academia de París no está incluido en Obras. La cita dice: «Los resultados de la suerte ambigua se atribuyen, pues, con razón, a la contingencia fortuita antes que a la necesidad natural.»].

${ }^{26}$ Tal será el caso de los autores de la segunda mitad del siglo XVII que justificarán esta misma relación considerando el dado como un objeto físico, y sometido como tal a las leyes generales de la Naturaleza.

27 «Enimvero multa sunt alia humana negotia licita quæ dubiæ illi varietati committuntur (...). Et (...) contractus assecurationis maritimarum mercium uno Doctorum consensu tanquam licitus habetur in quo tamen plurimum dominatur humano loquendi more fortuna» (Soto, loc. 
cómo se yuxtapondrían, dentro de la categoría de lo incierto, los juegos de azar con otras actividades humanas donde el azar, en su sentido estricto, no tiene lugar. En los tratados De Iustitia et Iure encontraremos, a menudo, unos tras otros los capítulos sobre las apuestas, los juegos de azar, los contratos de seguros, y las pensiones.

Viajemos ahora mentalmente hasta principios del siglo XVIII, y abramos la Dissertatio inauguralis mathematico-juridica de usu artis conjectandi in jure ${ }^{28}$, publicada en 1709 por Nicolás Bernoulli: encontramos allí rúbricas semejantes. ¿Diremos, como es costumbre, que «aplicaba» una nueva técnica a los asuntos jurídicos? ¿No sería más exacto decir que tal aplicación fue posible, presentándose naturalmente al espíritu de Leibniz, Montmort, Jacques Bernoulli, etc., porque los juristas les habían abierto hacía ya mucho tiempo el camino?

Leibniz proclamó que había encontrado en los jurisconsultos modelos de Lógica relativos a las cuestiones contingentes ${ }^{29}$. En el De conditionibus, publicado en 1665, formalizo, de algún modo, la teoría jurídica de la condición y ya entrevió entonces, antes incluso de haber adquirido una formación matemática, los principios del cálculo de probabilidades ${ }^{30}$. Tan ilustre caso nos permite pensar que la reflexión jurídica había emprendido una conceptuación de las situaciones de incertidumbre. Lo sorprendente sería lo contrario: la gigantesca empresa de codificación que representa el derecho romano no podía dejar de encontrárselas. Bastaba con fijarse en las palabras para encontrar allí reglas, principios, conceptos referentes a problemas análogos a los que tratará el ars conjectandi. Así, por ejemplo, la conditio, un acontecimiento futuro sobre el que hay incertidumbre an y quando; el periculum, las diferentes clases de spes, el principio Commodum esse debet cujus periculum... ${ }^{31}$. A causa de una evolución tanto económica como ideológica, ya en la Edad Media, y sobre todo después en el Renacimiento, algunas de estas nociones adquieren una importancia creciente. Así, por ejemplo, la noción de

cit.). [ «Ciertamente, otros muchos asuntos humanos, que son lícitos, se suelen confiar a la incertidumbre de la suerte.(...) Y existe también el contrato de seguro para las mercancías que se trasladan por mar, (...), el cual todos los doctores reconocen unánimemente como lícito, a pesar de que en él interviene grandemente la suerte, según la manera de hablar entre los hombres» (loc.cit)]

${ }^{28}$ [Hay una cuidada edición a cargo de Norbert Meusnier: N.Bernoulli, L'Usage de l'ars conjectandi en droit (Paris: CAMS, 1992)].

29 Cf. Louis Couturat, La Logique de Leibniz d'après des documents inèdits (París: Alcan, 1901), p. 241. [Reimpresión en Hildesheim: Olms, 1969; también en Leibniz, Sämtliche Schriften und Briefe (AA VI, 1)].

30 Ibid, nota V, pp. 553-554.

31 Habremos de pensar que la lección de Leibniz había caído completamente en el olvido. Ha sido un economista quien, lamentándose de la falta de formación probabilística de los juristas puros, les invitaba recientemente a releer el Digesto: de aqui extrae H. Guitton dos textos donde se discuten las dificultades relativas a los acontecimientos inciertos: el caso de un padre que muere dejando un solo hijo y una mujer embarazada y, en segundo lugar, la venta de un producto futuro ( «Le droit Roman en face de l'aléa», Revue Française de Recherche Opérationnelle, 27 (1963), 194-195). 
riesgo está en el mismo centro de los debates sobre la usura. Muy pronto se admitió que, en los contratos de sociedad, quien confía una suma de dinero a un mercader (sin cederle su propiedad, participando, por tanto, en los riesgos y peligros de la empresa) tiene derecho a reclamar una parte del beneficio. «Este riesgo, el periculum sortis, cuya importancia se aprecia progresivamente a medida que se van comprendiendo mejor los mecanismos económicos y monetarios, constituye la base de la doctrina de la Iglesia respecto al comercio y la banca. Bastaba que hubiese alguna duda sobre el resultado de una operación-ratio incertitudinis-y que la Iglesia reconociese que podía ser inherente a la actividad del mercader, para que estuviese justificada la percepción de un interés» ${ }^{32}$. A decir verdad, hizo falta mucho tiempo y hubo que dar muchas vueltas para que algunas prácticas dejasen de ser consideradas usurarias. Sabemos bien cuán tortuosos fueron los argumentos desarrollados por los casuistas para legitimar contratos reprobados por la doctrina tradicional: fueron estigmatizados en las Provinciales. Pero ¿no debía verse en la casuística nada más que una obra diabólica destinada a favorecer el espíritu de lucro? En numerosos ámbitos, su cometido fue, en realidad, codificar situaciones nuevas. La «aventura» había adquirido cada vez mayor importancia con el desarrollo de las grandes empresas comerciales. Las técnicas financieras se habían perfeccionado, en especial con la extensión de las letras de cambio. Aunque los escolásticos se negaban a admitir que la duración tuviese consecuencias económicas en las que pudiera basarse una diferencia de precio, una vez tuvo lugar un crecimiento neto del volumen y complejidad de los intercambios, se hizo manifiesto que podía obtenerse un beneficio de las diferencias de tiempo y lugar. Para establecer las reglas correspondientes a los nuevos tipos de operación, la teoría de los contratos debía ampliarse, atendiendo al papel cada vez mayor de los elementos «casuales». Si consideramos, además, que la pasión por el juego es «uno de los comportamientos colectivos típicos de la época», podríamos preguntarnos, con P. Jeannin, si no nos indicará un rasgo distintivo de la mentalidad del mercader del siglo XVI: «El desarrollo de la especulación, que a menudo se presenta como un rasgo de modernidad, está ligado, en realidad, a la presencia del azar, del juego, en el corazón mismo de los negocios, en formas que el siglo XVI hereda de la Edad Media» ${ }^{33}$. Por añadidura, la incertidumbre de las comunicaciones, los «peligros y fortunas del mar», impulsan la creación de instituciones destinadas a reducir la dependencia del hombre «respecto a los azares del mundo». De este modo, se extienden los contratos de seguros, compitiendo con el sistema más antiguo, de los préstamos a la gruesa (prêt à la grosse aventure). «En suma, se introduce en el seno del azar un mayor grado de racionalidad» ${ }^{34}$. Añadiremos, por nuestra parte, que dicha racionalidad se manifiesta en una contabilidad original, que evaluará «riesgos» y «esperanzas». Así, para

32 Jacques Le Goff, Marchands et banquiers au Moyen Age (París: PUF, 1962), p. 78 [Versión española: Mercaderes y banqueros de la Edad Media (Barcelona: Oikos-Tau, 1991)].

33 Pierre Jeannin, Les Marchands au XVI siècle (París: Seuil, 1963), p. 127.

34 Ibid., p. 131. 
determinar el modo en que las partes contratantes de una sociedad deben repartirse sus beneficios ${ }^{35}$ será necesario diferenciar los distintos tipos de contrato según los riesgos que corra, por un lado, quien aporta trabajo o esfuerzo, y por otro, quien aporta el capital, estableciendo reglas para combinar ambos elementos ${ }^{36}$. Estos problemas de distribución (partage) no están ya lejos del problema de los repartos (partis).

Desde este momento, se esboza alrededor de este problema lo que, a nuestro entender, puede considerarse con razón como su auténtico contexto. Antes incluso de que Pascal se decidiese a tratarlo, se había constituido un campo nocional (champ notionnel) bien definido, cuyo tema constitutivo era el hombre ante la incertidumbre. Correlativamente, se esbozaron métodos más eficaces de organización, una forma nueva de contabilidad que, de algún modo, exigía un cálculo más elaborado.

\section{PORVENIR DESFUTURIZADO Y CIENCIA DE LA ACCIÓN}

¿Qué hemos conseguido al determinar este contexto? Todos sabemos que las ciencias se engendran en un estadio precientífico, en el que una inteligencia aún corta de vista iba todavía al colegio, y resolvía a tientas, en una perspectiva utilitaria, problemas muy concretos. Pero el geómetra, para llegar a serlo, debe olvidar su pasado de agrimensor. Del mismo modo, ¿no debieran, en rigor, abandonar la mesa de juego el probabilista y el estadístico?

Si el cálculo de probabilidades no encuentra su formulación positiva sino en el «análisis estadístico», si su perfección no llega más que con el desarrollo de la mecánica estadística, entonces el carácter práctico de sus orígenes es un defecto que debemos por fuerza eliminar. Así lo afirma vigorosamente Brunschvicg en L'Experience humaine et la causalité physique: «el cálculo de

35 Más adelante tendremos ocasión de citar un texto de Lessio relativo a esta cuestión. [Cf. infra \$5].

36 Estas reglas debían servir como base para calcular de un modo efectivo según las proporciones justas, las partes correspendientes a cada cual. El deseo de satisfacer lo mejor posible las exigencias de la justicia distributiva condujo naturalmente al espíritu a liberarse de principios excesivamente simples. Señalemos a estos efectos una observación de Grocio -que también se encuentra en otros autores- referente a un problema análogo al de los repartos: ¿cómo efectuar un reparto si no ha sido explícitamente previsto en la convención? «Les Jurisconsultes disent que quand on n'a point déterminé la portion que doit avoir chaque Associé, ils sont censez être convenus de partager également. Cela n'est vrai que quand ils ont également contribué au fonds commun» (Grocio, Le Droit de la guerre et de la paix, ed. Jean Barbeyrac [Amsterdam: P.de Coup, 1724], vol.I, p. 438) [Versión castellana en 4 volúmenes a cargo de J.Torrubiano: El derecho de la guerra y de la paz (Madrid: Reus, 1925); la cita corresponde al Libro II, cap. XII, \$24: «Y lo que ha dicho el jurisconsulto que, no habiendo señalado las partes, se entiende que son iguales, únicamente se ha de tener por verdadero si las cosas que se aportan son iguales» (vol. 2, p. 218)]. Para justificar la misma tesis, Étienne Pasquier ahizo andar la sociedad contractual, en su pequefiez, sobre los pies de la sociedad universal, en su grandeza», aplicando a la primera la distinción de dos justicias, conmutativa y distributiva, que todo el mundo admite en la segunda (L'interprétation des Institutes de Justinian [Paris: A.Durand, 1847], L. III. cap. 40) [Ginebra: Slatkine, 1970, reimp.]. 
probabilidades entró en su edad positiva el día en que se estableció la separación entre los métodos generales de relación que caracterizan dicho cálculo y el carácter particular, diría incluso que pintoresco, de los problemas a los que tales métodos se aplicaron inicialmente» ${ }^{37}$. Pascal no habría hecho sino abrir camino, evitando especular sobre un acontecimiento único, la probabilidad singular. "Mucho más atrevido desde un punto de vista filosófico y más fecundo también en sus resultados» es el paso dado por Jean de Witt al aplicar la nueva disciplina a los datos de la experiencia ${ }^{38}$. $Y$ aunque no hay ningún aspecto positivo en sus especulaciones, Daniel Bernoulli anunció con su Hydrodynamica seu de viribus et motibus fluidorum commentarii el tiempo en que los métodos estadísticos, estrechamente asociados a la auténtica experimentación, servirían de fundamento a una nueva rama de la física matemática ${ }^{39}$. Al reprocharle Brunschvicg a Comte no haber sabido establecer las notas positivas del cálculo de probabilidades, le concedía, no obstante, una excusa: a principios del XIX, «en el estado en que éste entonces estaba, podía aparecer como el tipo de ejercicios puramente especulativos cuyo único resultado era retrasar o dificultar la reforma de la filosofía de la física» ${ }^{40}$.

Un caso para la reflexión del historiador de las ciencias: en nombre de una «filosofía», se pone en la picota todo un conjunto de investigaciones toda la corriente de pensamiento invocada por la teoría de la decisión. No nos corresponde pronunciarnos sobre el punto de vista general en virtud del cual Brunschvicg separa el grano de la paja: mas, de resultas, ¿no se le habrá escapado también el auténtico punto de vista pascaliano? Lo que a Brunschivcg le parece esencial en su método es que en éste el porvenir aparece «como desfuturizado (défuturisé); el azar, desprobabilizado (deprobabilisé)» ${ }^{41}$. Si la partida hubiese seguido su curso normal, habríamos visto «el azar en marcha en el sentido de lo más o lo menos probable», se habrían dado ganadores y perdedores. Por el contrario, para repartir lo apostado cuando la partida se interrumpe, no necesitaríamos más que el aspecto abstracto e intemporal de la idea de azar. «No especulamos, por tanto, sobre el futuro; lo suprimimos al proyectarlo, de algún modo, sobre el plano del presente; el coeficiente de incertidumbre inherente al riesgo del juego, transformado en una especie de materia inerte y fija, se convierte en objeto de un cálculo certero, que arranca toda esperanza y todo temor de los jugadores, toda oposición entre adversarios» ${ }^{42}$. A primera vista, el análisis es irreprochable. Cuando representamos lo que podría ocurrir, al enumerar las diferentes posibilidades, «desfuturizamos» el porvenir. Por otra parte, la 358.

${ }^{37}$ L. Brunschvicg, L'experience humaine et la causalité physique (París: P.U.F., 1949), p.

38 Ibid., p.355.

39 Ibid., p.359.

40 Ibid., p.359. Brunschvicg, aquí de acuerdo con Comte, negaba explícitamente la posibilidad de una teoría de la decisión: «A.Comte tiene razón también al pensar que al orientar nuestra vida, las circunstancias de la acción rara vez están suficientemente bien definidas como para permitimos basar nuestra decisión sobre un cálculo preciso» (Ibid., p.354).

${ }^{41}$ Ibid., p. 355.

${ }^{42}$ Ibid., p.355. 
ambición del árbitro que debe fijar los repartos (partis) es, por supuesto, fundar su respuesta sobre un cálculo certero. Si interpretamos, por tanto, que los jugadores se embolsarán la suma que con éste se les atribuye, admitiremos también que corta de raíz todas sus esperanzas y temores. Pero al adelantarnos al momento del reparto, olvidamos la cláusula fundamental que establece su equidad: «(...) la determinación de lo que debe corresponderles debe estar de tal modo proporcionada con lo que tenían derecho a esperar de la suerte que cada uno de ellos encuentre enteramente igual tomar lo que se le asigna o continuar la aventura del juego (...)» ${ }^{43}$. Una vez establecida esta proporción, un tercer jugador podrá reemplazar equitativamente en mitad de la partida a uno de nuestros dos jugadores, comprando al justo precio su «derecho de esperar» (droit d'espérer). Aquel que deje la partida no tendrá nada que temer o esperar, pero no ocurrirá lo mismo con quien le reemplace.... No es, por tanto, en la «desfuturización» del porvenir donde radica el aspecto central del método. Una vez establecida la regla de los repartos, el árbitro puede cambiar de papel, dejando el de Salomón por el de Consejero del Príncipe: al jugador enfrentado a un porvenir incierto, puede prescribirle la mejor acción. La regla de los repartos (partis) es al mismo tiempo una regla de las apuestas (paris).

Tan claramente lo apreciaron los sucesores de Pascal que esta última expresión aparecerá con toda naturalidad en sus escritos ${ }^{44}$. Pero no es en absoluto necesario buscar fuera de la obra de Pascal la fecunda ambigüedad de la palabra partida (parti), a la vez «reparto» y «elección». Que la regla de los repartos sea una regla de las apuestas se dice literalmente en sus Pensamientos. Pascal va aun más lejos, prestándole un valor normativo más fuerte: no sólo puede orientar a quien toma partido, demuestra también que debemos trabajar por lo inseguro: «San Agustín ha visto que se trabaja para lo inseguro en el mar, en las batallas, etc. pero no ha visto la regla de los repartos que demuestra qué se debe hacen ${ }^{45}$. El tono es el del maestro que conoce la «razones de los efectos». Podríamos dejarnos llevar y, volviendo de nuevo a la interpretación de Bruschvicg, poner el acento únicamente sobre el «demuestra» olvidando el «debe». Así lo hace, entre otros, Jean Guitton: «En la Geometria Aleae, Pascal no ve un medio para construir una lógica de lo incierto que pueda ayudar al espíritu a decidirse en asuntos concretos, extendiendo del presente al futuro el dominio de nuestra información, sino al contrario, un procedimiento para destruir toda probabilidad concreta

43 Pascal, G.E., III, p. 478. [Obras, p. 693].

44 El caballero de Mére «formuló las primeras proposiciones sobre la estimación de las apuestas" (Leibniz, Die philosophischen Schriften, ed.Gerhardt, vol. IV [Reimpresión en Hildesheim, N.York: Georg Olms, 1978], p. 570). Cuando Montmort «se llevó a Nicolas Bernoulli en campaña», su «incesante batallar con los problemas» tuvo por objeto *estimar los riesgos (hazards), regular las apuestas...» (Fontenelle, «Éloge de Montmort», en Idem, Ouvres [París: Ed. Jean-François Bastien \& Jean Servière, 1792], vol. 7, p.52) [Hay una edición en curso de las obras completas de Fontenelle en el Corpus des ouvres de philosophie en langue francaise, a cargo de A.Niderst et al., Paris: Fayard, 1990-ss].

${ }_{45}$ Pascal, Pensamientos (Br.234, La. 577) [Obras, p. 529]. Cf. también: «Ahora bien, cuando trabajamos para el mañana y para lo inseguro obramos con razón, porque se debe trabajar para lo inseguro según la regla de los repartos, que está demostrada» (loc.cit.). [loc. cit.]. 
alcanzando de golpe la certeza apodíctica» ${ }^{46}$. Se advierte con claridad cómo se puede acabar reteniendo del método pascaliano únicamente el triunfo de la certeza. ¡Con qué tono concluyente no afirmaría Pascal que su método era «demostrativo»! Al proclamar la victoria de la Razón sobre la Fortuna, dejaría explotar su entusiasmo de campeón de la rectitud geométrica:

Eam quippe tanta securitate in artem per Geometriam reduximus, ut certitudinis ejus participes facta, jam audacter prodeat ${ }^{47}$.

Cotejando esto con la aversión que manifestaban los probabilistas hacia el autor de las Provinciales, le declararíamos «antiprobabilista»: tan pronto como encontraba una pizca de probabilidad, «su enfado le impulsaba a deshacerse cuanto antes de esa molesta cantidad» ${ }^{48}$. En fin, la misma intervención del infinito en el cálculo, en el argumento de la apuesta, puede darnos la impresión de que Pascal se dejaba arrastrar por su pasión demostrativa al extremo de eliminar el sentido de las propias circunstancias que dieron origen al problema: «es una especulación que suprime el riesgo» ${ }^{49}$. Ante este género de argumentos, que muy a menudo encontramos en numerosos intérpretes, hay que responder, en general, que una vez introducido el azar, nada puede expulsarlo. En nombre de la razón, el árbitro-consejero impone una elección, pero quien le obedezca se arriesga a recibir una decepción. La Geometria aleae comparte con la geometría la evidencia apodíctica, pero no elimina, sin embargo, el azar. Pascal pudo ser antiprobabilista al extremo de eliminar la palabra probabilidad de su vocabulario: está convencido de que el cálculo matemático de los «azares» es riguroso. Pero no es antiprobabilista, si con ello se quiere decir que el destino de su nuevo arte era eliminar todo riesgo. El riesgo es consustancial a las cosas que hacemos por «lo inseguro en el mar, en las batallas» ${ }^{50}$. La incertidumbre se refiere aquí al hacer, no al conocer. Quienes han visto en la parte matemática del fragmento «infinito-nada» ${ }^{51}$ que Pascal quería proporcionarle al libertino una actitud ventajosa aciertan a efectuar esta distinción: «el objeto de la Apuesta no es inducir al incrédulo a creer en Dios, sino conducirle a comportarse como si creyese y, en consecuencia, a conformarse al género de vida cristiano» 52 . Leibniz afirmaba ya: «la conclusión de este argumento no se refiere a nada que debamos creer, sino solamente a lo que debemos hacer» ${ }^{53}$.

46 Jean Guitton, Pascal et Leibniz. Etude sur deux types de penseurs (Paris: Aubier, 1951), p. 64.

${ }^{47}$ Pascal, G.E., III, p. 307. [La cita corresponde al Discurso a la Academia de Paris (cf. supra nota 22), Dice: «Hemos reducido con seguridad mediante la geometría [la cuestión del azar] a un arte, haciéndola partícipe de su certeza, de modo tal que ahora progresa audazmentem].

48 J. Guitton, op.cit., p. 64.

49 Loc.cit.

50 Pascal, Pensamientos (Br 234, La 577). [Obras, p.529]

51 [Br. 233, La. 418 (Obras, p. 458)].

52 Roger-E. Lacombe, L'apologetique de Pascal. Étude critique (París: P.U.F., 1958), p.73.

53 Carta al Duque Juan-Federico de Hannover, hacia 1678 (Leibniz, Allgemeiner Politischer und Historischer Briefwechsel, Deutsche Akademie der Wissenschaften zu Berlin (hg.) 
 (...) ${ }^{54}$
\& sic matheseos demonstrationes cum aleae incertitudine jungendo

Conjugar decisiones y acontecimientos inciertos: ese es el fin perseguido por Pascal. No hay ningún abuso interpretativo al afirmarlo. Al contrario, los textos se explican mejor leyéndolos en esta perspectiva. Cuando oponemos ciencia y práctica, sin dejar espacio a la teoría de la decisión, nos vemos abocados o bien a rechazar como metafísicas las «trazas» que ha dejado la «práctica» en el arte de establecer los repartos, o bien a condenar a Pascal por abuso de la Geometría. Lo cierto es que si Pascal hizo entrar una ciencia en su estadio positivo, no se trataba de la ciencia que Brunschvicg pensaba.

Podemos afirmar con igual seguridad que los textos de Pascal pueden servir de hilo conductor a una exposición introductoria del Cálculo de probabilidades, considerado como un capítulo de la teoría matemática de la decisión 55 . En vez de buscar anticipaciones marginales de una ciencia, tomémoslos, pues, como ellos mismos se nos ofrecen: como la solución de un problema de reparto, y no como una teoría sobre el concepto de probabilidad.

\section{SEGURIDAD Y FORTUNA}

Desde este punto de vista vamos a considerar lo que Pascal, en su correspondencia con Fermat, denominaba, respecto al método de las 'combinaciones', «(...) mi otro método universal al que nada escapa y lleva su demostración consigo» ${ }^{56}$. Puesto que no tenemos ya motivo para desconfiar de su impureza pragmática, estudiaremos si los importantes nexos que acabamos de encontrar entre las nociones de justicia, suerte, convención e incertidumbre, pueden ayudarnos a esclarecer la elaboración del método pascaliano.

El juego consiste en una sucesión de «partidas». En cualquier momento, pongamos A, sabríamos enumerar las secuencias de posibles sucesos. ¿Qué puede ocurrir si los jugadores continuasen, en A, con «la aventura del juego»?

[Darmstadt, 1927], vol.II, p.112). [Reimpresión en Berlin, Hildesheim, New York: Akademie Verlag \& Georg Olms Verlag, 1970].

54 Pascal, G.E., III, pp. 307-308. [Esta frase continúa el pasaje anteriormente citado (cf. supra nota 22) del Discurso a la Academia de Parts (1654): «Así, conjugando la demostración matemática con la incertidumbre del azar (...)»]

${ }_{55} \mathrm{M}$. Barbut, «De Pascal à Savage, un chapitre de l'algebre linéaire: le calcul des probabilités (cas fini)», Mathematica \& Paedagogia 31 (1966), 7-20. Este artículo quiere «sugerirles a los docentes una vía menos clásica (aunque muy antigua, 1654, y bastante natural) que la que siguen la mayoría de los manuales de introducción al cálculo de probabilidades». Se define, en principio, un espacio vectorial de apuestas; la esperanza se introduce como la forma lineal positiva que aplica el vector de apuestas en el cuerpo que representa la escala de utilidades; basándonos en el principio de Pascal se define la regla de concatenación de esperanzas

$$
\text { [A saber: } \mathrm{E}_{\mathrm{A}}=\sum_{i=l}^{r} \mathrm{P}_{\mathrm{A}}\left(\mathrm{A}_{\mathrm{j}}\right) \mathrm{E}_{\mathrm{Aj}} \text { ] }
$$


Se nos ofrecen entonces dos posibilidades, según el ganador haya sido Primus o Secundus. Supongamos que sabemos cómo se distribuiría en ambos casos -sean B y C, respectivamente- el montante de las 64 monedas que constituyen la apuesta. Si se da el caso B, Primus recibe las 64 monedas, y Secundus ninguna; si es $C$, Primus recibe 48 monedas y Secundus 16. Lo representaremos mediante el siguiente esquema:

$$
\mathrm{B=64+0} \quad \text { (C) }=48+16
$$

Comprobaremos que, ocurra lo que ocurra, Primus recibirá al menos 48 monedas. Para el caso en que, dado A, los jugadores no deseasen jugar otra partida, Pascal le presta el siguiente razonamiento a Primus:

(...) Debe decir así: «Si la gano, ganaré todo, que es 64 pistolas; si la pierdo, me corresponderán legitimamente 48: por lo tanto, dadme las 48 pistolas que tengo seguras y repartamos las otras 16 por la mitad, puesto que hay tanta probabilidadad de que las ganéis vos como de que las gane yo». Así pues, tendrá 48 más 8 que son 56 pistolas ${ }^{57}$.

$$
(A)=56+8
$$

Para este otro ejemplo, baste representar los datos en un esquema semejante al anterior:

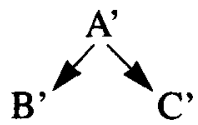$$
\left(B^{\prime}\right)=56+8
$$$$
\left(C^{\prime}\right)=32+32
$$

Si se diese el caso A' y los jugadores no deseasen jugar otra partida, Primus le podría decir a Secundus:

Si no queréis jugarla, dadme 32 pistolas que me corresponden seguras y repartamos el resto de 56 por la mitad: de 56 quitad 32, quedan 24; repartid pues 24 por la mitad, tomad 12 y yo 12 , que con las 32 hacen $44{ }^{58}$.

$$
\left(A^{\prime}\right)=44+20
$$

56 Carta a Fermat, 24 de agosto de 1654 (Pascal, G.E., p. 404). [Obras, p. 668].

57 Carta a Fermat, 29 de julio de 1654 (Pascal, G.E., p. 383). [Obras, p. 660. La pistola (pistole) es una antigua moneda de oro].

58 Loc.cit. [loc.cit.]. Sobre el método de Pascal, cf. G.-Th.Guilbaud, «Leçons sur les éléments principaux de la théorie mathematique des jeux», en VV.AA., Stratégies de décisions économiques. Études théoriques et applications aux entreprises (Paris: Éditions du C.N.R.S., 1954); P. Rosenstiehl, «Jeux et Mathématiques», en Jeux et Sports (París: Gallimard [Encyclopedie de la Pléiade], 1967.), pp. 829-834. 
Tanto en sus «principios» como en los razonamientos que les presta a sus jugadores, Pascal establece una distinción esencial entre los casos en los que cabe apoyarse en alguna certeza, y aquellos en que debemos contentarnos con la incertidumbre. No se trata en absoluto, como antes advertimos, de negarla radicalmente. Antes bien, nos parece que es en esa dualidad de lo cierto y lo incierto donde radica el auténtico nervio del método pascaliano. Su naturaleza es más compleja de lo que aparenta, y desde un principio reserva sorpresas al cartesiano más austero.

¿Queremos determinar lo desconocido a partir de lo conocido, según una regla fundamental del Método ${ }^{59}$ ? No tomaremos en cuenta más que las partidas ganadas. ¿No es evidente, en principio, que disponemos en ellas de una medida de la ventaja de cada jugador? Ahora bien, «no se debe propiamente tener en cuenta más que el número de partidas que les quedan por jugar al uno y al otro, y no el número de las que han ganado" ${ }^{60}$. Si Pascal se cuidó de formular y demostrar esta proposición, es porque atenta contra una visión inicial, demasiado simplista, del problema. De hecho, entre los predecesores de Pascal, sólo Cardano lo había advertido ${ }^{61}$. La dificultad radicaba en que había de invertirse un movimiento natural del espíritu: «la genialidad consiste en proceder en sentido inverso al curso del tiempo, determinar lo cierto a partir de lo incierto, el presente desde el futuro» ${ }^{62}$. P. Massé explica muy bien la originalidad de esta aproximación, oponiéndola al punto de vista del físico, para quien los acontecimientos se ordenan uno tras otro siguiendo el curso natural del tiempo, y al del economista, para quien los valores proceden unos de otros en sentido inverso al del tiempo ${ }^{63}$. Pero «determinar lo cierto desde lo incierto» plantea una dificultad aun mayor. Esta fórmula paradójica nos recordará los múltiples debates a que ha dado lugar la «ciencia de lo probable»: cierta tradición nos ha acostumbrado a creer que tenía por objeto principal la previsión. Pero al considerar a Pascal desde tal punto de vista, se toma un camino equivocado.

Pascal emplea la palabra «cierto» (certain) en dos sentidos muy diferentes. Se jacta de que su arte participa de la «certeza de la geometría», pero su jugador basa sus cálculos sobre una certeza muy diferente cuando exige:

59 [Las tesis cartesianas sobre el conocimiento probable pueden verse, por ejemplo, en la segunda de las Regulae ad directionem ingenii, Adam-Tannery X].

60 Pascal, G.E., III, p. 482. [Obras, p. 695].

61 "Quantum ac rationem ludorum sciendum est quod in ludis non habet considerari nisi terminus ad quem (...)»[En lo que se refiere a la razón de los juegos, hemos de saber que en los juegos no ha de considerarse lo que se tiene, sino lo que se tendrá] (Opera Omnia [Lyon: J.-A. Huguetan \& M.A. Ravaud, 1663] vol. IV, p. 112). Cf. E. Coumet, «Le problème des partis avant Pascal», Archives internationales d'histoire des sciences 72-73 (1965), 245-272. [Hay una versión castellana del Liber de ludo aleae en M.S. de Mora Charles, ed., Los inicios de la teoría de la probabilidad (Servicio editorial de la Universidad del País Vasco, 1989), pp. 22-57].

62 P. Massé, «En lisant Pascal», Revue Française de Recherche Operationelle 24 (1962), p. 201.

${ }^{63}$ Loc. cit.. P .Massé cita a Irving Fisher: «La cosecha de trigo depende de la tierra que la provee. Pero el valor de la cosecha no está en función de la tierra. Por el contrario, el valor de la tierra depende del valor conjetural de las cosechas». 
«Deme las 48 monedas que tengo aseguradas (qui me sont certaines), incluso en el caso de que pierda» o, dicho de otro modo, «estoy seguro de tenerlas, puesto que incluso perdiendo las obtendré», esas monedas son mías "con seguridad». Abreviando, podríamos denominar certeza-seguridad (certitudesûreté) esta certeza que corresponde a un título de propiedad.

$\mathrm{Si}$ a un jugador le corresponde cierta suma, gane o pierda, «debe considerarla íntegramente asegurada». ¿Qué es entonces la incertidumbre? «La incertidumbre es aquello que obra y da lugar al reparto (parti) que determina exactamente qué corresponde a cada cual» ${ }^{64}$. Es el estado del hombre que no puede prever qué le asignará la fortuna. Ahora bien, «la incertidumbre de ganar es proporcional a la certeza de lo que arriesgamos según la proporción de los riesgos (hasard) de ganancia y pérdida» ${ }^{65}$. Este es el nudo del problema. Es necesario distinguir dos vertientes en el modo en el que se relacionan aquí certidumbre e incertidumbre, según pensemos en el primer o en el segundo sentido de la palabra certidumbre. Fijar la distribución justa consiste en establecer una suma que se me «asegura», y me será indiferente embolsármela o arriesgarla en un juego justo (equitable). Hay aquí equivalencia entre estas dos «condiciones» (conditions). Esta equivalencia puede calificarse de «cierta», si es exacta. Fijar la distribución justa consiste en establecer una equivalencia cierta (de una certeza geométrica) entre una condición en la cual me embolso el dinero apostado (certidumbre-seguridad) y otra en la que continúo jugando (incertidumbre de la fortuna).

Este análisis, de por sí tosco (haría falta disponer de una lógica modal más fina para poder descomponer el «arte» de Pascal en todas sus articulaciones), intenta simplemente poner de manifiesto en qué momento, antes incluso de que aparezca una medida numérica, se ponen en relación globalmente dos situaciones de tipo muy diferente. Notemos, de paso, que Huygens se apoya en idéntica relación para calcular el «valor» de las «esperas» (attentes) de los jugadores:

Hoc autem (...) utar fundamento: nimirum, in aleae ludo tanti aestimandam esse cujusque sortem seu expectationem ad aliquid obtinendum, quantum si habeat, possit denuo ad similem sortem seu expectationem pervenire, aequa conditione certans.

«Fundamento» del que Huygens deduce inmediatamente la siguiente proposición:

Si a vel b expectem, quorum utrumvis aeque facile mihi obtingere possit, expectatio mea dicenda est valere $(a+b) / 2^{66}$.

\footnotetext{
64 Frase tachada por Pascal: Pensamientos, edición de L.Lafuma (París: Ed. du Luxembourg, 1951), p. 239.

${ }^{65}$ Cf. la carta de Pascal a Fermat del 29 de julio de 1654 (Pascal, G.E., III, pp. 382-383) [Obras, pp. 658-1666].

${ }^{66}$ C. Huygens, «De ratiociniis in ludo alea», en F. Schooten, Exercitationum Mathematicarum libri quinque (Leiden: Johannes Elsevirii, 1657), p. 522. [El primer pasaje dice: «Me
} 
Vemos, por tanto, qué rodeo permitirá comparar lo seguro y lo incierto: se trata esencialmente de confrontar valores y establecer reglas de intercambio. Este es también el espíritu del método pascaliano, pero en él se ve con menor claridad el papel que desempeña un "punto de indiferencia» introducido subrepticiamente. Cuando Pascal enuncia su segundo principio ${ }^{67}$, da la impresión de expresar una evidencia natural. Invirtamos, de algún modo, este principio para ver un segundo aspecto del mismo, como «regla de apuestas», y su evidencia resultará menos convincente.

La sabiduría popular le opondrá nada menos que un proverbio: «Más vale pájaro en mano que ciento volando». Sin ninguna duda, Pascal experiment 6 lo chocante que puede resultar comparar una cantidad asegurada con otra que arriesgamos. Pero dijo con toda claridad qué pensaba de ello, refiriéndose no sólo al jugador: «todo jugador arriesga seguramente (avec certitude) para ganar con inseguridad (avec incertitude), y sin embargo arriesga seguramente lo finito para ganar seguramente lo finito", cuidándose de añadir en letra pequeña: «sin pecar contra la razón» ${ }^{68}$. Al criticar la principal de las «razones morales» propuestas por Pascal, el abate Villars señalaba, no sin cierta perspicacia:

(...) Toda su fuerza depende de la verdad de esta proposición, que todo jugador arriesga seguramente para ganar con inseguridad sin pecar contra la razón. En verdad, Paschase, si la divinidad fuese tan problemática como esta proposición, tendríamos problemas. Todos los padres y maridos que no quieren que sus hijos o mujeres jueguen serían ateos natos. Ellos os replicarian obstinadamente que es una sinrazón arriesgar un dinero que tenemos asegurado en el bolsillo, con el cual podemos vivir de espaldas a la miseria, para ganar un dinero incierto; exponerse, como ocurre a menudo, a no tener ni uno ni lo otro ${ }^{69}$.

El argumento no es sólo de naturaleza moral y no se refiere exclusivamente a los juegos de azar. Traduce, en realidad -numerosos textos relativos a la apuesta (pari) podrían atestiguarlo- un sentimiento más profundo: hay una enorme disimetría entre las situaciones de incertidumbre y aquellas en las que, por el momento, estamos seguros de la posesión de un bien. Algunas controversias recientes han devuelto a la actualidad este problema de forma especialmente aguda: el cálculo de probabilidades ya se había encontrado con

sirvo (...) de este fundamento: ciertamente, en los juegos de azar la suerte o esperanza de obtener algo ha de estimarse en aquello que, de poseerlo, permitiría alcanzar la misma suerte de nuevom. El segundo dice: «Si espero a $\sigma b$, y puedo obtener con igual facilidad cualquiera de las dos, se dirá que mi esperanza vale $(a+b) / 2 »$. Hay una versión íntegra en español: «Del cálculo en los juegos de azar», en M.S. de Mora Charles, ed., op cit. , pp. 107-134].

${ }^{67}$ [Cf. Obras, p. 693].

68 Cf. G. Brunet, Le Pari de Pascal (París: Desclee de Brouwer, 1956), p. 20. (La cita de Pascal en Obras, p. 461).

${ }^{69}$ Abate Villars, De la Délicatesse (París: Claude Barbin, 1671), pp. 356-358. [Véase D.Descotes, La Première critique des «Pensées»: texte et commentaire du cinquième dialogue du traité «De la Délicatesse» de l'abbé de Villars (1671) (París: Éditions du CNRS, 1980)]. 
él, mas de un modo marginal, en forma de paradojas, de objeciones del buen sentido (bon sens), o dudas manifestadas por filósofos. Para la teoría de la decisión se trata, al contrario, de un problema interno y esencial. Así se pudo apreciar en el Congreso de Econometría de $1952^{70}$, al debatirse las tesis de la «Escuela Americana» en las que se identificaban ciertas construcciones matemáticas, muy hermosas por lo demás, con una teoría general del comportamiento racional. Maurice Allais, en particular, impugnaba animosamente que sólo se considerasen elecciones racionales aquellas que respetaran la «formulación de Bernoulli» ${ }^{71}$. La observación psicológica del comportamiento de personas sumamente prudentes y el examen de «elecciones aleatorias frente a otras ciertas» (choix aléatoires au voisinage de la certitude) ponen en cuestión tal definición de racionalidad ${ }^{72}$. Estas simples alusiones ilustran el auténtico alcance de la situación en la que se encontraba Pascal. Se pudo reprochar a la Escuela americana su excesiva sensibilidad a la «belleza de una construcción matemática sumamente general» que ella misma había fabricado. ¿No resulta verosímil pensar que si Pascal concede un valor normativo a su arte, es porque él mismo se sorprendía de haber conseguido «componer azares», de haber ordenado cursos aleatorios complejos en un sistema extremadamente coherente?

Mas ¿sobre qué base descansaba esta coherencia? ¿Cómo es posible que el argumento de un propietario que habla de pérdidas y ganancias desemboque en el mismo orden numérico que reina en el triángulo aritmético? ¿Cómo pudieron llegar casi a confundirse aquellos dos sentidos que distinguíamos en la palabra «certeza»?

\section{LA LÓGICA JURÍDICA DE LA INCERTIDUMBRE}

¿Diremos acaso que el juego nos ofrecía naturalmente un «modelo» de particular simplicidad? «Hay combinaciones artificiosas a las que dan lugar nuestros juegos de convención (jeux de convention), como en aquellos ejemplos escolásticos en los cuales hubiera sido pueril aplicar un aparato de razonamiento formal, puesto que, por su propia simplicidad, resultaban especial-

${ }^{70}$ Cf. VV.AA., Econométrie [Colloques internationaux du CNRS, XL; París, 12-17 Mai 1952] (París: Editions du CNRS, 1953).

${ }^{71}$ Cf. especialmente la exposición sintética que aparece como apéndice en el volumen antes citado (supra nota 67): «Fondements d'une theorie positive des choix comportant un risque, et critique des postulats et axiomes de l'école americaine».

${ }_{72}$ «La experiencia muestra que gente muy prudente y considerada por el común como racionales puede preferir $\mathbf{4 0}$ francos asegurados a una oportunidad entre dos de ganar 100 francos o incluso 400 asegurados a una oportunidad entre dos de ganar 1000». (Se trata de una oferta única que no se repite) «Esta comprobación experimental es incontestable, y no se entiende cómo, desde un punto de vista racional, puede criticarse a un individuo que tiene una señalada preferencia por la seguridad. Tal comportamiento pone en cuestión la posición fundamental de la Escuela americana» (Op.cit., p.313).

73 A.A. Cournot, Considérations sur la marche des idées et des événements dans les tempos modernes (París: Boivin \& Cie., 1934), vol.I, p. 231. [Cf. supra nota 4]. 
mente adecuados para evidenciar los mecanismos del razonamiento» ${ }^{73}$. Pero ¿bastaba con que las reglas fuesen simples para poner de manifiesto los razonamientos empleados en el juego? Se trataba, en efecto, de razonar sobre el juego, y aun en el caso de que alguna vez existiese un jugador dotado de lo que Fontenelle denominaba -a propósito de Dangeu - «un álgebra natural» ${ }^{74}$, estaría demasiado interesado en sus perdidas o ganancias para remontarse a los principios. Para que esto resultara posible, fue necesario ponerse en la posición del espectador, convertirse, como Pascal, en árbitro imparcial. Pero, una vez distanciado, ¿basta con interrogar a la propia inteligencia? Tanto la racionalidad lógica como la sabiduría razonable niegan el postulado que Pascal nos propone: no admiten que algo incierto pueda igualarse a algo cierto. ¿Hemos de creer, entonces, que hubo de forjar en solitario sus propias razones?

Es el momento de recordar que Pascal se expresaba al modo de los juristas. Ahora bien, ¿se trataba simplemente de un préstamo linguíístico? La «ley voluntaria» a la que se refiere ${ }^{75}$, ¿es algo más que una cómoda imagen con la que describir las condiciones del problema? La facilidad con la que leerá "consecuencias» en los «se sigue» convencionales, nos hará sospechar más bien lo contrario. Su arte consiste en aprovechar esa suerte de complicidad que une aquí al jurista y al geómetra: ambos hablan de igualdad y proporción. La intervención del geómetra en un dominio ajeno no parecerá en ningún caso una intrusión: al contrario, en realidad, la justicia se imparte mediante sus ajustes. Esto no debiera hacernos olvidar que el jurista había hecho ya la mitad del trabajo. Expresiones como «igual», «derecho de esperar», «asegurado», «propiedad», «proporcionado» están cargados de teoría y concentran, si nos fijamos, toda una serie de deducciones y experiencias. En el problema que ahora nos ocupa, ¿no podríamos decir que éstas, al menos indirectamente -acaso por sugestión-, habrían ayudado, orientado y guiado incluso, al geómetra?

Según una doctrina considerada durante mucho tiempo intocable, un Contrato de Sociedad es inicuo si la parte contratante que aporta su dinero quiere participar también en las ganancias eventuales y recuperar, en cualquier caso, su capital.

Aquel que contribuyere con cien escudos a la sociedad, y quisiera recuperarlos sin que a ello afecte contingencia alguna, y no obstante, si hubiere un beneficio, quisiera tener su parte, incurriría en ruin usura: pues él aseguraría su parte, y al mismo tiempo querría ganar contra el derecho de sociedad, que establece que el riesgo (hazard) de desastre o beneficio sea compartido por los socios ${ }^{76}$.

\footnotetext{
${ }^{74}$ Fontenelle, Euvres (Paŕs: Jean-François Bastien \& Jean Sevière, 1792), vol.7, p. 103. [Cf.supra nota 41]

75 (Cf. supra nota 20].

76 «Celuy qui contribue en societé 1000 escuts, desquels il veut estre remboursé quelque fortune qu'il puisse arriver \& nonobstant s'il y a du proffit il en veut avoir sa part, il commet une meschante usure: car il met tousiours le sien en assurance \& temps-pendant veut gagner contre le droit de societé, qui veut que le hazard du dommage, ou du profit, soit commun entre les compagnons» (J. Bénédicti, La somme des péchez et le remède d'iceux... [París: Chapelet, 1601], p. 332).
} 
Hemos subrayado en este pasaje expresiones que nos recuerdan aquellas de las que se sirvió Pascal, pero más que el encontrarlas aquí, nos importa la presencia de un concepto lógico que interviene muy a menudo en los debates sobre la usura. Se trata de una modalidad que los lógicos no se han cuidado de señalar explícitamente, cuya importancia para la teoría de la elección fue, no obstante, aclarada por L.J.Savage al definir su «Principio de seguridad» (Sure-thing Principle) ${ }^{77}$ : se trata del «sea lo que fuere lo que ocurra» (quoi $q u$ 'il arrive) en una situación de incertidumbre determinada. De este modo, el primer principio de Pascal, en apariencia elaborado para un caso concreto y con un alcance restringido, nos remite a una categoría lógica que desempeña un importante papel en la teoría de los contratos. ¿No ocurrirá lo mismo con aquella regla de intercambio entre circunstancias iguales a cuya función nos referíamos antes?

Para dar respuesta a esta pregunta, ¿podremos encontrar mejor experto que Domat, amigo de Pascal y, a la vez, uno de los más sabios juristas de la época? Su respuesta merece ser transcrita por entero:

En las convenciones donde se trate de un derecho o de otra cosa que dependa de algún acontecimiento incierto, y donde de ello puedan resultar beneficios o pérdidas, según los diferentes sucesos, se es libre de pactar de forma que, por ejemplo, uno renuncie a todo provecho y evite toda pérdi$\mathrm{da}$, o que acepte una suma por todo lo que pudiera esperar ganar, o una pérdida previamente regulada (reglée) por todas aquellas que pudiese temer. Así, un socio que desee retirarse de una sociedad puede regular (régler) con los demás asociados qué beneficio seguro le corresponderá o con qué perdidas cargará, sean cuales fueren los acontecimientos que se produjeran. Así, un heredero puede llegar por una cierta suma a un trato con los coherederos acerca de sus derechos en la sucesión, y obligarles a exonerarle de todas las pérdidas. Y estas formas de convención son justas en lo referente a que, ante la incierta espera de los acontecimientos, uno elija un reparto seguro (parti certain) y conocido, sea de ganancias o de pérdidas, y otro aproveche la ventaja de optar por aguardar la condición (condition) mejor. Pues de este modo se establece una especie de igualdad entre sus opciones que hace justa su convención ${ }^{78}$.

Las analogías entre este pasaje y el «Uso del triángulo aritmético...» son tan llamativas que cabría preguntarse incluso si no le deberá Domat a Pascal

${ }^{77}$ L.J. Savage, The Foundations of Statistics (N. York: John Wiley \& Sons, 1954) [Savage formula así este principio en las páginas 21-22 de la segunda edición revisada, aparecida en Dover Publications en 1972: sean $\mathbf{f}, \mathbf{g}$ acciones, «si una persona no prefiriese $\mathbf{f}$ a $\mathbf{g}$, tanto sabiendo que se había dado el suceso $B$, como sabiendo que se había dado el suceso $\sim B$, entonces no prefiere $\mathbf{f}$ a g. Más aún (supuesto que no considerase $B$ como virtualmente imposible) si definitivamente prefiriese $g$ a $f$, sabiendo que se había dado $B$, y no prefiriese $f \mathbf{~ a ~} g$, sabiendo que $B$ no se había dado, entonces preferiría definitivamente $g$ a fm.]

78 Jean Domat, Les lois civiles dans leur ordre naturel (Paris: J.-B.Coignard, 1689-1694), Lib. I, pp. 97-98. [Hay una antigua versión castellana en 2 volúmenes: Las leyes civiles en su orden natural. Obra escrita en francés por $J$. Domat y arreglada para el uso de los españoles por Don F.Villarrubias y Don J.Sarda (Barcelona: Esteban Pujol, ${ }^{3} 1861$ )]. 
la claridad con la que formula lo que él mismo denomina una regla (règle). Sea lo que fuere, Domat se da por satisfecho con expresar fielmente la sustancia de las disposiciones y leyes tradicionales: de este modo confirma, si es que era aún necesario, que el problema de los repartos no es una dificultad bizantina, inventada caprichosamente. Del texto vamos a retener, sobre todo, aquello que en él buscábamos: el establecimiento de una igualdad entre una «parte segura» y una «espera incierta». Sin embargo, es evidente que en este punto estamos aún muy lejos de disponer de criterios precisos que permitan «sopesar» con exactitud las «lesiones» y las «ventajas».

Igualmente delicado resultaba evaluar el «justo precio» (juste prix) que debía pagarse por un "peligro» (péril). Esta es la razón por la cual, ante la imposibilidad de poder considerar todas las circunstancias particulares, los casuistas a menudo recurrían bien a la buena fe de los contratantes, bien a la autoridad de los comerciantes más prudentes; o bien, puesto que admitían que por el peligro que se corría al prestar una suma «debía pagarse tanto como se estimase el valor del riesgo (hazard)", se atienen a consideraciones del más y el menos ${ }^{79}$. Sin embargo, en ocasiones iban más allá en su análisis. Por ejemplo, en los casos en el que el periculum sortis, incierto como es por naturale$\mathrm{za}$, se expresaba por un precio «cierto» (certain). Así, sea un contrato de sociedad en el cual quien aporte 1.000 monedas de oro soportará en solitario la pérdida de esa suma, si aconteciese una desgracia. Debiendo considerar las posibles pérdidas para determinar cómo habría de hacerse un reparto justo de los beneficios, Lessius afirma que el peligro debiera estimarse en 100 monedas de oro.

Le objetaremos, entonces, que son 1000 y no 100 las monedas que perderá una de las partes, si no le sonriese la fortuna. «Respondeo, Periculum sortis incertum debet reduci ad certum pretium (...)» ${ }^{80}$. Esta condición se puede satisfacer imaginando un contrato de seguro mediante el cual quien

79 «Cuál es el precio que debe ofrecerse a quienes asumen los peligros y otros acontecimientos fortuitos a los que está sujeto el comercio, y en especial, el dinero; cuál es la suma proporcional a la ganancia indefinida e incierta que nos prometemos con 100 escudos, entregados a una Sociedad Comercial. Habrá de consultarse con la propia conciencia y con expertos. En general, podemos decir que debe igualarse a la esperanza que se tenga de obtener más o menos beneficios. Decía Maior en la quaestio 49: 'con una ganancia cierta de muchos, puede tener valor un beneficio incierto en expectativa, que debe dismuir según la magnitud del riesgo'» [ Quel est le prix qu'on doit offrir à ceux qui se chargent des perils, \& autres événements fortuits ausquels chaque chose est sujette dans le commerce, $\&$ nommement l'argent, quelle est la somme proportionnée au gain indéfiny, \& certain, qu'on se promet des cent escus, baillez au titre de Societé du Marchand. L'on consultera de cela sa conscience, et les experts; généralement l'on peut dire, qu'il la faut égaler à l'espérance, que l'on a, d'en tirer plus ou moins de profit, quia multorum lucro certo, potest lucrum in spe incertum valere, \& secundum magnitudinum periculi diminuendum est lucrum istud] (Etienne Bauny, Somme des pechez qui se commettent en tous estats de leurs conditions et qualitez et en quelles occurences ils sont mortels ou veniels (París: M.Soly, 1653), p. 227).

${ }_{80}$ «Respondo: el incierto peligro de la suerte debe ser reducido a un precio cierto (...)» (Lessio, De Iustitia et lure caterisque virtutibus cardinalibus [Lovaina: J.Masius, 1605], libri IV, p. 310). 
aporte un capital a la empresa pudiese resguardar su dinero: la prima que habría de pagarle a un posible asegurador, estimada aquí en 100 monedas de oro, establece también el valor de la única pérdida eventual que debiera tomarse en consideración para decidir, en justicia, la parte del beneficio a la que su inversión le da derecho. Este era un procedimiento caro a los casuistas: pasar de lo incierto a lo cierto, de lo arriesgado a lo asegurado, rodeando por un contrato auxiliar. Este ejemplo ilustra los originales métodos de análisis y síntesis a través de los cuales el pensamiento jurídico descompone una convención en sus elementos simples y puede, por tanto, aplicarse a una situación compleja. ¿Acaso Pascal liga de otro modo sus repartos (partis) a otros posibles repartos, previamente establecidos? ¿No es componiendo progresivamente contratos auxiliares como llega a determinar cómo se aplicaría en cada caso la convención inicial?

Acaso nos preguntemos si tiene sentido comparar la sorprendente precisión de este método con el simplicísimo procedimiento de Lessius. Tomemos ejemplo de Pascal y distingamos los «principios» de la «pura aritmética». No en vano sugeríamos que los principios del arte pascaliano operaban ya en el antiguo arte, sutil a su modo, de las transacciones: ¿no pudo servirle de guía, acaso indirectamente, la lógica de la incertidumbre que gobernaba éste?

\section{LA COMPOSICIÓN DE MAGNITUDES DESEMEJANTES}

Hay, sin embargo, una noción que proviene aun más directamente de la especulación propiamente matemática, por la operación que la define y por los cálculos que posibilita. Pero no debiéramos apresurarnos a denotarla con un nombre que nos resulta ya familiar. Muchos comentaristas afirman, con alguna ironía por otra parte, que Pascal se dio por satisfecho «aplicando» la noción «elemental» de esperanza matemática. Más bien, la inventó en el momento mismo en el que exploraba sus posibilidades. En su formulación matemática, muy pronto se hizo «elemental», pero en tanto que concepto fundamental de la praxeología su manejo es aún hoy muy delicado como para que no hubiese ofrecido ya en el S. XVII grandes dificultades epistemológicas. Intentaremos mostrarlo a través del testimonio de algunos textos.

Las reflexiones sobre la equidad de los juegos de azar «parecen de escaso valor y, en efecto, lo son si en ellas nos detenemos. Pero podemos ponerlas en función de cuestiones más importantes. Y el principal uso que de ellas debe obtenerse es el de hacernos más razonables en nuestras esperanzas y nuestros temores» ${ }^{81}$. Por tanto, ni la originalidad ni el alcance general de la Geometria alea habían escapado a la perspicacia de los autores de El arte de Pensar: estas novedades matemáticas aparecieron en el momento preciso para servir de base a las reglas del Método que se refieren al «juicio que debemos

81 A. Arnauld \& P. Nicole, La Logique ou l'Art de Penser, IV, cap.XVI, edición crítica de P. Clair y F. Girbal (París: PUF, 1965), p. 354. [Tomamos la traducción de la edición española a cargo de Guillermo Quintás: La lógica o el arte de pensar (Madrid: Alfaguara, 1987), p. 490]. 
hacer de los accidentes futuros» ${ }^{82}$. Del mismo modo que las reglas para pensar correctamente (bien penser) disipan los errores de los sentidos, las reglas para obrar correctamente nos permiten denunciar las ilusiones de las que mucha gente es víctima,

(...) ilusión que es tanto más engañosa cuanto más razonable les parece. No consideran más que la importancia y las secuelas de la ventaja que ellos desean, sin apreciar en forma alguna la apariencia y la probabilidad que hay de que este inconveniente acontezca o no ${ }^{83}$.

Temen una calamidad, y helos ya cargados de incómodas y excesivas precauciones, aun cuando el acontecimiento que temen sea poco probable. Y si, al contrario, les deslumbra la magnitud de la ventaja que les es posible obtener, descuidarán por completo la probabilidad de que el acontecimiento les sea favorable, incluso si ésta fuese extremadamente pequeña.

El defecto de estos razonamientos reside en que para juzgar acerca de lo que se debe hacer para obtener un bien o para evitar un mal, no sólo es preciso considerar el bien o el mal en sí mismos; además es necesario valorar la probabilidad de que suceda o no suceda y analizar geométricamente la proporción que todas estas cosas guardan ${ }^{84}$.

Así, por ejemplo, puede mostrarse que «en esa clase de juegos que llamamos loterias», «la totalidad de los jugadores se engaña», puesto que no es un juego equitativo. Advertiremos el carácter normativo que se atribuye al cálculo de probabilidad (hasards): en efecto, a lo largo de toda su historia, encontramos calculadores que critican vivamente las «ilusiones de los jugadores». Una psicología del riesgo más refinada nos ha enseñado a evitar juicios excesivamente apresurados sobre este asunto, pero, desde un punto de vista histórico, entendemos que estas «ilusiones» deben ser consideradas, efectivamente, como obstáculos: sólo luchando contra ellas se pudo imponer la idea, clara y distinta, de la proporción geométrica. La tarea era ardua, puesto que aquello que convenía conceptuar como «proporción» no era, a primera vista, sino un sentimiento: la esperanza ante una fortuna incierta. Si habitualmente se le reprocha al geómetra su abstracción, cuánto más reprochable parecerá en este caso. La recta geométrica imita la plomada, mientras que la ficción con la que distraemos al jugador no se corresponde con ninguno de los estados que puede asignarle efectivamente la fortuna. La esperanza matemática no traduce una previsión, no se refiere a otra cosa que a un estado virtual. La fuerte hostilidad con la que ha sido recibida recientemente la «concepción subjetiva» de la probabilidad muestra qué potencia pueden tener este tipo de objeciones, aun cuando por entonces la noción de frecuencia no había hecho

82 [Ibid, pp. 487-492].

83 Op. cit.., p. 353. [Ibid., p. 488].

84 Ibid., p. 353. [Ibid., p. 489]. 
aún su aparición en este campo. Sabemos solamente que Pascal fue objeto de las críticas del caballero de Mére, que no era geómetra («como vos sabéis, es un gran defecto»). Roberval, en cambio, sí lo era, pero también él, según un testimonio de Leibniz que a menudo se omite, volvía la cara ante estas novedades:

Demonstrato ergo tantum nos in bonis habere videri, quanta est habendi probabilitas, et tantum nobis de re abesse videri, quanta est amittendi probabilitas (nam hoc erat illud de quo memini Robervallium dubitasse (...) ${ }^{85}$.

Los motivos de la duda no se detallan, pero recordemos que Roberval manifestó la sospecha de que Pascal y Fermat «habían incurrido en un paralogismo» al pretender que la justicia de una partida dependiese de una «condición ficticia»: jugar cuatro partidas, cuando la «condición natural del juego» es que se interrumpa cuando uno de los jugadores haya ganado ${ }^{86}$.

Habría quizá que ver en esta desconfianza ante una «ficción» -todo el método reposa sobre convenciones ficticias- algo más que una objeción ocasional ${ }^{87}$ : un indicio de la aversión a pasar del punto de vista del juego que se desarrolla efectivamente al del «game», el «juego por jugar» («jeu à jouer»); un indicio del sentimiento de que hay peligro al razonar sobre posibilidades, al extraer consecuencias desde una perspectiva tan irrealista ${ }^{88}$.

Sólo audaces geómetras pudieron llevar a término este combate por la abstracción. Pero, en cierto modo, les fue además necesario ejercer de geómetras contra la geometría. Puesto que las magnitudes -y la palabra es ya demasiado precisa- que había que «componer» diferían entre sí profundamente por su naturaleza, sus fuentes, y su modo de ser. Como insiste a este respecto un pasaje de los Nuevos ensayos sobre el entendimiento humano, se

85 «Por consiguiente, está demostrado que tanto más nos parece poseer un bien, cuanto mayor es la probabilidad de poseerlo, y tanto más nos parece que se aleja, cuanta mayor es la probabilidad de perderlo (recuerdo que era de esto de lo que dudaba Roberval)' (L.Couturat, ed., Opuscules et fragments inédits de Leibniz [París: Alcan, 1903], p. 569). [Reimpresión en Hildesheim, N. York: Georg Olms, 1988; De Incerti Aestimatione tiene ya una edición crítica íntegra en: Leibniz, Vorausedition, vol. VI, (Münster, 1991), pp. 2.720-2.729].

${ }^{86}$ Pascal, G.E., III, p. 404. [Obras, p. 668].

87 Leibniz aludía quizá a estas objeciones cuando escribía: «(...) los bellos pensamientos sobre el Alea de los señores Fermat, Pascal y Huygens, que el señor Roberval no podía o no quería comprender en absoluto (...)" (Opera Omnia, ed.Dutens, vol.II, parte I, p. 92) [O también Leibniz, Die philosophischen Schriften, ed.Gerhardt, vol. IV (Hildesheim, N. York: Georg Olms, 1978), p. 570]. «El pasaje de Pascal no bastaría para justificar suficientemente el alegato de Leibniz« (G.E., III, p. 403, nota 1) [Se refiere al pasaje contenido en Obras, p.668]. Observación que suscribiríamos, más aún después de considerar el texto del De incerti estimatione [cf. supra nota 82], que nos ofrece, creemos, la fuente exacta del alegato.

${ }^{88}$ I.Todhunter apunta que la objeción de Roberval la retomaría D'Alembert (A history of the mathematical theory of probability: from the time of Pascal to that of Laplace [Cambridge \& Londres: McMillan \& Co., 1865], p. 14). [Reimpresión en N. York: Chelsea Publishing Company, 1965]. 
trata de magnitudes heterogéneas. Filaletes indica. que arriesgar un bien mayor por uno menor, sin haberlos examinado cuidadosamente, es obrar directamente contra la razón.

El sabio Teófilo le responde:

Como la consideración de la magnitud de la consecuencia y de la magnitud del consecuente son dos consideraciones heterogéneas (es decir, no pueden ser comparadas juntas), los moralistas se han embrollado bastante al quererlas comparar, como se ve en los que han escrito sobre la probabilidad. La verdad es que aquí, como en otras estimaciones dispares y heterogéneas, $y$, por así decirlo, de más de una dimensión, la magnitud de que se trate está en razón compuesta de una y otra estimación, como en un rectángulo, donde hay dos consideraciones, a saber, la longitud y la anchura. En cuanto a la magnitud de la consecuencia y de los grados de probabilidad, todavía carecemos de la parte de la lógica que pueda estimarlos ${ }^{89}$.

Este precioso texto nos enseña, ante todo, cuán difícil podía resultar pensar en una relación de este tipo sin ayuda de la conceptuación matemática. Los propios términos de la relación no pudieron distinguirse claramente hasta después de la intervención de los matemáticos, lo cual resulta aún más sorprendente, puesto que la distinción de probabilidad y utilidad se considera absolutamente clara, en átención a su importancia en la historia del cálculo de probabilidades. Merecería la pena analizar la incomodidad de los «probabilistas», según sugiere Leibniz: veríamos que la composición de estimaciones dispares encuentra dificultades mucho más serias que las ilusiones psicológicas denunciadas por Arnauld y Nicole: son los propios conceptos de la filosofía tradicional los que se adaptan mal a problemas que hasta entonces estaban fuera de su horizonte.

Para convencerse, bastaría espigar algunos comentarios de entre los muchos que, aún en nuestros días, se amontonan sobre el «argumento de la apuesta» ${ }^{90}$. Baste como prueba el testimonio del padre Mauduit, que escribía a finales del XVII. Es cierto que desarrollo su argumento en veinte capítulos (aunque torpemente) ${ }^{91}$. Es cierto también que se cuidó de evitar la palabra

${ }^{89}$ Leibniz, Nouveaux Essais sur l'entendement humain, (En Euvres philosophiques de Leibniz, ed.Janet [Paris: Librairie philosophique de Ladrange, 1866] vol.1, p.185). [Edición española de Javier Echeverria (cf. supra nota 2): Nuevos ensayos sobre el entendimiento humano, Libro II, capítulo XXI, \& 66, p. 234]

90 Sin tener siquiera en cuenta la distancia que separa en el propio Pascal el susodicho argumento y el concepto matemático de apuesta. Cf. G.-G.Granger, Pensée formalle et sciences de l'homme (París: Aubier-Montaigne, 1960), pp. 70-71; H.Gouhier, Blaise Pascal. Commentaires (París: Vrin, 1966), pp. 279-ss.

91 Michel Mauduit, Traité de la religión contre les athées, les déistes et les nouveaux pyrrhoniens. Nouvelle éditión augmentée de plusieurs demonstrations et de réponses a de nouvelles objections (Paris: L.Roulland, 1699). [Hay una edición crítica comentada a cargo de Mi-ae Hyun (Clermont-Ferrand: Association des publ.de la Faculté des lettres et sciences humaines de Clermont-Ferrand, 1996)]. 
apuesta, y se jacta de no haber adoptado «la apariencia de juego» que Pascal «le da a su razonamiento»: sus torpezas resultan muy instructivas para nosotros. Agradezcámosle, en todo caso, el cuidado que se toma en exponer las máximas fundamentales según las que debe comportarse el hombre prudente, de acuerdo con la moral tradicional. De este modo, nos mostrará la contradicción en la que la propia moral se ve envuelta cuando intenta reprender a los casuistas al tiempo que defender a los libertinos. La regla fundamental de la prudencia es: «Entre dos repartos dudosos, debemos escoger siempre el más seguro» ${ }^{92}$. Sobre tal máxima se fundaba la actitud tuciorista, y en su nombre condenaron los adversarios de los probabilistas «las dudosas vías que los nuevos casuistas han abierto».

Es una imprudencia, en caso de duda, abandonar las opciones seguras por aquellas que son simplemente probables ${ }^{93}$.

Henos aquí, sin embargo, con que aparece un libertino que, irónicamente, interpretará el tuciorismo en provecho propio. ¡ Reprochen a esos impios escoger «la más peligrosa entre dos vías inciertas»!

Se defenderán entonces con esa otra máxima del buen sentido, que no es sino una explicación de la primera: corresponde a la Prudencia preferir siempre lo cierto a lo incierto... Como ellos aplican esta incertidumbre a la vida futura, concluyen que no hay nada comparable a disfrutar reposadamente de las mieles de la vida presente, sin preocuparse de un futuro que es incierto, puesto que debemos preferir el presente al futuro, un presente asegurado a un futuro que no lo está ${ }^{94}$.

El libertino parece haber puesto a la Prudencia de su lado; y el moralista parece haberse visto sorprendido de que una de sus reglas se vuelva contra él: no podrá evitar este paso en falso, sino negándose a reconocer esta regla como suya. $\mathrm{O}$, al menos, deberá sacrificar la claúsula «siempre» que en ella se incluye. Para convencer a su adversario, se verá obligado a defender que hay casos en los que corresponde a la Prudencia preferir lo incierto a lo cierto.

¡Afirmación absolutamente paradojica en boca del Prudente! Ahora resulta que quien gustosamente confundía sabiduría (sagesse) y tranquilidad, está dispuesto a tomar por testigo a los que «arriesgan»: los Mercaderes, el Piloto, el Soldado, e incluso los Conquistadores, que abandonan la certeza «renunciando a la paz que disfrutaban en sus Estados de origen, para embarcarse en

\footnotetext{
92 «Que de deux partis douteux il faut toujours choisir le plus sâr» (ibid., p.47).

93 «C'est une imprudence dans le doute de quitter les sûres, pour celles qui sont simplement probables» (ibid., pp. 177-178).

94 «Alors ils se défendent par cette autre maxime du bon sens, qui n'est en effet qu'une explication de la première, qu'il est de la Prudence de preferir toujours le certain à l'incertain.... Et comme ils appliquent cette incertitude à la vie future, ils concluent qu'il n'est rien tel que de goûter en repos les douceurs de la vie présente qui son assurées, sans se mettre en peine de l'avenir qui est incertain, parce qu'on doit preférer le présent à l'avenir, un présent assuré à une avenir qui ne l'est pas» (ibid., p.47).
} 
expediciones de éxito dudoso» ${ }^{95}$. Preferían racionalmente la esperanza razonable de obtener un gran bien a obtener uno de menor valor. Hay que distinguir, por tanto, diferentes casos según tratemos de fines o de medios.

Si convenimos en el fin, y dudamos sólo de los medios para llegar a él, es una tremenda imprudencia abandonar lo cierto por lo incierto (...) ${ }^{96}$.

Pero si no convenimos en el fin perseguido, y el espíritu, oscilando entre los muchos que se le ofrecen, busca a cuál debe ligarse, debemos discernir si estos fines son iguales, o si el bien que esperamos no es mucho más ventajoso que aquel que arriesgamos: en este caso, es aún preferible lo cierto a lo incierto (...) ${ }^{97}$.

Por último, si los fines son desiguales, si el bien esperado sobrepasa ostensiblemente al que ya poseemos, debemos preferir el primero por incierto que sea; porque, considerándolo globalmente, la magnitud del bien que esperamos es una ventaja mucho mayor que la certidumbre del bien que ya poseemos ${ }^{98}$.

Mauduit no había escuchado los consejos del Arte de pensar: no contaba con los diferentes grados de probabilidad. No obstante, su texto puede servirnos para ilustrar la hipótesis siguiente: la objeción del libertino que entiende "la certeza en el sentido de certeza-seguridad antes apuntado, subvierte la economía tradicional de la prudencia. El problema deja de ser qué debemos hacer cuando estamos seguros de conocer la verdad. Es fácil responder en este caso, que hemos de contentarnos con la probabilidad mayor; lo más probable se confunde así con lo más seguro. Pero si uno se pregunta en qué casos debe abandonarse lo cierto por lo incierto, será necesario considerar los bienes y los males. El problema se complica: por decirlo esquemáticamente, supongamos que disponemos no de una, sino de dos escalas, una para la probabilidad y otra para las utilidades; convendrá "componer» sus respectivas graduaciones. Lo más seguro deja entonces de ser lo más probable, y la presencia de un riesgo no puede ya ocultarse. El lenguaje de la filosofía clásica duda: habiendo meditado esencialmente sobre la acción moral, ésta plantea el problema de la acción desde una lógica de la verdad. En el momento en que ya no se trata de optar por lo más cercano a la verdad, le resulta difícil incluso formular el problema. El

95 «Lorsqu'ils ont renoncé à la paix ils jouissoient dans leurs Etats, pour s'engager en des expéditions dont le succès étoit très douteux» (ibid., p. 50).

96 «Si l'on convient de la fin \& que l'on doute seulement des moyens d'y arriver, c'est une haute imprudence de quitter le certain pour l'incertain (...)» (ibid., p. 176).

97 «Mais lorsqu'on ne convient plus de la fin ou l'on tend, \& que l'esprit, comme en balance entre plusieurs qui se proposent, cherche à laquelle il doit s'attacher; on doit concevoir si ces fins sont égales, ou si le bien qu'on espère n'est guère plus avantageux que celui qu'on hazarde: \& en ce cas il faut encore préférer le certain à l'incertain (...)» (ibid., p. 178).

98 «Enfin, si les fins sont inégales, si le bien espéré surpasse notablement celui qu'on possède, on doit préférer le premier tout incertain qu'il soit; parce que tout considéré la grandeur du bien qu'on espère est un plus grand avantage que la certitude du petit bien qu'on possède»" (ibid., p. 180). 
ejemplo de Mauduit ilustra a qué extremo los conceptos de fin y medio se muestran insuficientes.

La ciencia de la decisión se dio a conocer en una crisis de la Prudencia, cuando se presentaron a la razón situaciones en las que se debía «trabajar por lo inseguro». Se trata de hacer, y no de creer.

Pues se trata de dos cuestiones completamente separadas, saber qué es, en la práctica, lo más seguro, y qué es, en cuestión de creencias, lo más probable. Los mismos casuistas han insistido mucho en esta distinción. Pues a menudo estamos obligados a seguir lo más seguro, aun cuando no sea lo más probable ${ }^{99}$.

\section{FINAL}

Mediante un doble movimiento, consistente en sugerir, por un lado, una ampliación del ámbito en el que se inscribe el problema de los repartos, y acotando máximamente, por otro, el sentido de los principios pascalianos, hemos intentado alejarnos de la anécdota (la inauguración de la Geometria Aleae).

$\mathrm{Si}$, contrariamente a la opinión de Cournot, su aparición no fue tan sólo una afortunada casualidad, es porque el juego de azar no es una institución inerte, de la que podamos asegurar despreocupadamente que ha permanecido idéntica a sí misma a lo largo del tiempo. El «juego de puro azar» que Pascal encontró es un juego laicizado, separado de su aura mágico-teológica, al que se asignó un determinado lugar en el ámbito de las situaciones de incertidumbre, un juego refractado a través de la práctica y la teoría de los contratos aleatorios. Ahora bien, tanto la formulación como el léxico de los principios pascalianos indican su parentesco con la conceptuación jurídica previa del azar. Una vez descubierta, no es conveniente, creemos, despreciarla como tara de una invención matemática insuficientemente purificada. Las esperas de los jugadores, las reglas de intercambio entre condiciones distintas, no son apoyos externos ocasionales de una disciplina a la conquista de su autonomía, sino también instrumentos y objetos de un cálculo cuya significación y coherencia intrínsecas ha sido percibida por los probabilistas contemporáneos: un Cálculo de Esperanzas.

Hemos confirmado copiosamente que Pascal fue el iniciador de dicho cálculo. Como de costumbre, el efecto retroactivo de lo verdadero, la lectura recurrente - en el sentido de Bachelard- rinde beneficios por partida doble: una vez reactivados, los textos pascalianos pueden retomarse y desarrollarse en el discurso científico actual; su imagen, oscurecida por interpretaciones inexactas, se puede restaurar, restituyéndole su riqueza original. En todo caso, si nuestro análisis tiene parte de verdad, traicionaríamos su espíritu exten-

99 «Car ce sont deux questions tout à fait séparées, sçavoir ce qui est le plus seur dans la practique, \& sçavoir ce qui est le plus probable dans la créance. Ce que les casuistes mêmes ont fort bien distingué. Car souvent, on est obligé de suivre le plus seur, lors même qu'il n'est pas le plus probable» (Carta de Leibniz al duque Juan-Federico de Hannover; cf. supra nota 50). 
diendo en exceso sus resultados. Nos plantea, por el contrario, nuevos interrogantes, siempre en el terreno histórico: ¿es legítimo considerar en un mismo plano los descubrimientos de Pascal y el Ars Conjectandi de Jacques Bernoulli? ¿Hubo alguna relación entre los proyectos de aplicación a «los asuntos de la vida civil» de lo que después sería el cálculo de probabilidades y la conceptuación jurídica del azar anteriormente apuntada? Detengámonos también en el propio Pascal: nos hemos referido ocasionalmente a un método, el de «combinaciones», que bastaría para resolver el problema de los repartos; la concordancia entre dos métodos originados con distinto propósito carga de racionalidad las especulaciones de Pascal y Fermat; tal concordancia debe examinarse para autentificar la aparición de un cálculo dotado de consistencia propia, dejando definitivamente atrás las estimaciones de comerciantes o juristas. En su carta a Fermat del 29 de julio de 1654, decía Pascal: «Bien veo que la verdad es la misma en Tolouse que en París» ${ }^{100 .}$ 